\title{
Biosorption of Chromium from Aqueous Solution by Gracilaria corticata (Red Algae) and Its Statistical Analysis Using Response Surface Methodology
}

\author{
G. Kavitha, V. Sridevi, P. Venkateswarlu, N. Chitti Babu* \\ Department of Chemical Engineering, Andhra University, Visakhapatnam, India \\ Email: *nallurichitti@rediffmail.com
}

How to cite this paper: Kavitha, G., Sridevi, V., Venkateswarlu, P. and Chitti Babu, N. (2016) Biosorption of Chromium from Aqueous Solution by Gracilaria corticata (Red Algae) and Its Statistical Analysis Using Response Surface Methodology. Open Access Library Journal, 3: e2968.

http://dx.doi.org/10.4236/oalib.1102968

Received: August 11, 2016

Accepted: September 6, 2016

Published: September 9, 2016

Copyright $\odot 2016$ by authors and Open Access Library Inc.

This work is licensed under the Creative Commons Attribution International

License (CC BY 4.0).

http://creativecommons.org/licenses/by/4.0/

\begin{abstract}
The present work deals with, the potential of biosorption technique for the removal of chromium from aqueous solutions using marine based material viz. Gracilaria corticata powder. The experiments are carried out in a batch operation to understand the equilibrium studies, kinetics and thermodynamics of the biosorption. The maximum removal efficiency of $93.68 \%$ was obtained at a temperature of $323 \mathrm{~K}, \mathrm{pH} 4$, equilibrium time of $240 \mathrm{~min}$ and at an optimum biosorption dosage of $20 \mathrm{~g} / \mathrm{L}$ of 44 $\mu \mathrm{m}$ particle size. The percentage biosorption increases with an increase in initial concentration of chromium. The statistical analysis of biosorption using Response Surface Methodology (RSM) was studied. The theoretical and experimental values for \% biosorption of chromium were observed as $85.39 \%$ and $85.49 \%$ respectively. It is evident that experimental values of \% biosorption are in close agreement with that values predicted by Central Composite Design. The experimental data are well described by Freundlich, Langmuir and Redlich isotherm models. The biosorption data follows pseudo second order kinetics. Thermodynamic results showed that biosorption is endothermic, irreversible and feasible.
\end{abstract}

\section{Subject Areas}

Chemical Engineering \& Technology

\section{Keywords}

Biosorption, Gracilaria corticata, Response Surface Methodology (RSM), Central Composite Design (CCD), Equilibrium Studies, Kinetics, Thermodynamics 


\section{Introduction}

Contamination of aquatic environment by heavy metal ions is a worldwide environmental problem. Discharge of heavy metals in to the oceans, seas and rivers by many industries like leather tanning, textile dyeing, electroplating and metal finishing industries is continuous process by manmade activities. Chromium and its compounds are toxic metals introduced into natural water from a variety of industrial wastes leads to aquatic life threat. Chromium exists in two oxidation states: trivalent chromium $\mathrm{Cr}$ (III) and hexavalent chromium $\mathrm{Cr}(\mathrm{VI})$. The hexavalent chromium is 500 times more toxic than the trivalent chromium [1]. It causes many health problems for both aquatic animals and human beings. There are many conventional methods for minimizing heavy metals from industrial effluents like reverse osmosis, filtration, ion exchange, chemical precipitation, electro deposition, membrane systems and adsorption. Most of these methods suffer from drawbacks such as high capital and operational costs or the disposal of the residual metal sludge.

Biosorption is one of the conventional methods which can be performed at low cost using the natural biosorbents. From the literature, it is evident that many works are carried out using activated carbon for the removal of chromium from aqueous solution, but the activated carbon is economically not feasible. Hence the use of adsorbents which can be obtained naturally at low cost yields good results. Some of them are like: $20.92 \mathrm{mg} / \mathrm{g}$ maximum metal capacity was obtained by using powdered cotton stalk [3]; maximum metal uptake capacities of $0.77 \mathrm{mmol} / \mathrm{g}$ for $M$. pyrifera and $0.74 \mathrm{mmol} / \mathrm{g}$ for U. pinnatifida was observed [4]; $9.09 \mathrm{mg} / \mathrm{g}, 9.71 \mathrm{mg} / \mathrm{g}, 6.45 \mathrm{mg} / \mathrm{g}, 26.32 \mathrm{mg} / \mathrm{g}$ are the maximum metal uptake capacities obtained from various dried sea weeds i.e. Laminaria japonica, Undaria pinnatifida, Porphyra haitanensis, Gracilaria lemaneiformis respectively [5]; maximum metal uptake capacity of $14.54 \mathrm{mg} / \mathrm{g}$ was obtained by using Bacillus subtilis biomass [6]; similar results were also obtained by Pleurotus ostreatus [7], Streptomyces VITSVK9 spp. [8], Neem leaf powder [9], Sargassum sp. Biomass [10].

The present research work deals with the removal of chromium (VI) ions, which is a highly toxic metal from the aqueous solution using Gracilaria corticata (Red Algae). The characterization, the presence of functional groups and their structures were studied by X-Ray Diffraction (XRD), Fourier Transform Infrared Spectroscopy (FTIR) and Scanning Electron Microscope (SEM) analysis. It also deals with the biosorption studies, kinetics and thermodynamic process of the process. The theoretical studies using Response Surface Methodology (RSM) were also studied and the results are compared with experimental values.

\section{Materials and Methods}

\subsection{Preparation of Biosorbent}

Fresh samples of Gracilaria corticata, a species of the red algae were collected from Jodugullapalem beach in Visakhapatnam, Andhra Pradesh. The red algae were washed thoroughly with distilled water to remove sand and dirt completely. The cleaned red algae were dried in sunlight, until the moisture was completely removed. The dried 
biomass was ground to powder by using a mechanical grinder. The grounded powder was then sieved and $44 \mu \mathrm{m}$ size algae powder was used in the present study, and was separated using BSS sieves. The powder was then stored in air tight glass container at room temperature and used as biosorbent for subsequent analysis.

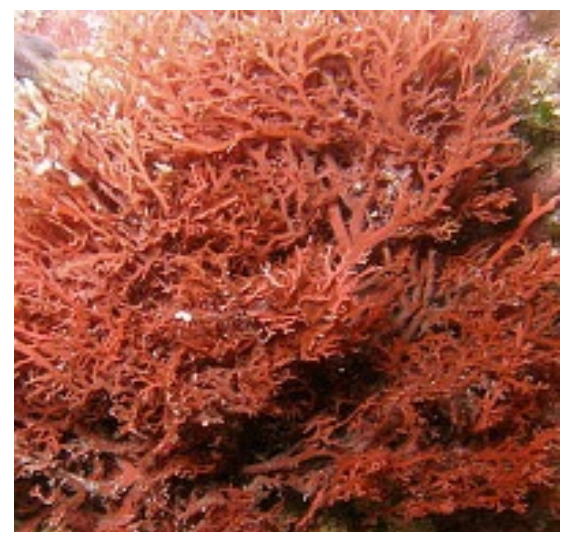

Gracilaria corticata (Red Algae)

\subsection{Preparation of Chromium Stock Solution}

Potassium dichromate $\left(\mathrm{K}_{2} \mathrm{Cr}_{2} \mathrm{O}_{7}\right)$ is used as the source of chromium stock solution. All the required solutions are prepared with double-distilled water. $2.828 \mathrm{~g}$ of $99.9 \%$ $\mathrm{K}_{2} \mathrm{Cr}_{2} \mathrm{O}_{7}$ is dissolved in $1 \mathrm{~L}$ of distilled water to prepare $1000 \mathrm{mg} / \mathrm{L}$ of Chromium stock solution. Samples of different concentrations of Chromium are prepared from this stock solution by appropriate dilutions. $50 \mathrm{mg} / \mathrm{L}$ of chromium solution is prepared by proper dilutions of $50 \mathrm{~mL}$ of $1000 \mathrm{mg} / \mathrm{L}$ Chromium stock solution is taken in a 1000 $\mathrm{mL}$ volumetric flask and is made up to the mark with distilled water. The $\mathrm{pH}$ of the aqueous solution is varied by adding required amounts of $0.1 \mathrm{NHCL}$ and $0.1 \mathrm{~N} \mathrm{NaOH}$.

$$
\text { Chromium equivalent to } 1000 \mathrm{mg} / \mathrm{L}=\frac{\text { Molecular weight of } \mathrm{K}_{2} \mathrm{Cr}_{2} \mathrm{O}_{7} \times 100}{\text { Atomic weight of } \mathrm{Cr} \times \text { purity }}
$$

\subsection{Characterization of Biosorbents}

\subsubsection{FTIR Studies}

The biosorbent characterization was done using spectrum GX (Perkin Elmer, USA) spectrophotometer from $400-4000 \mathrm{~cm}^{-1}$ with a resolution of $1 / \mathrm{cm}$ using four scans with back ground subtraction. The peaks were noted from the spectra by comparing it with literature reported spectra.

\subsubsection{X-Ray Diffraction Analysis (XRD)}

The XRD of biosorbent samples were obtained in X-Ray Diffractometer (Model: 2036E201; Rigaku, Ultima IV, Japan). The diffracted X-ray intensities were noted as a function of $2 \theta$ by using copper target $(\mathrm{Cu}-\mathrm{K} \alpha$ radiation with $\lambda=1.5492 \mathrm{~A})$ at a scan speed of $2^{\circ} / \mathrm{min}$. XRD patterns were recorded from $10^{\circ}$ to $80^{\circ}$. Different phases of the samples were identified by comparing with a set of " $\mathrm{d}$ " values and the corresponding intensities were identified from JCPD (Joint Committee on Powder Diffraction data) files. 


\subsubsection{Scanning Electron Microscope (SEM) Studies}

The pretreated biosorbent samples were examined in Scanning Electron Microscope, JEOL, JSM-6610, JAPAN and electron probe micro analyzer. The working height was $15 \mathrm{~mm}$ with a voltage ranging from 10 to $40 \mathrm{kV}$. The compositional image analyses of samples were also taken using same equipment at $20 \mathrm{kV}$ and $30-100 \mathrm{~mA}$ beam current.

\subsection{Biosorption Studies}

The procedures adopted to evaluate the effects of various parameters viz. agitation time $(t)$, biosorbent size $\left(\mathrm{d}_{\mathrm{p}}\right)$, biosorbent dosage $(\mathrm{w}), \mathrm{pH}$ of aqueous solution, initial concentration of metal in aqueous solution $\left(\mathrm{C}_{0}\right)$ and temperature of aqueous solution on biosorption of metal (chromium) were explained below.

\subsubsection{Effect of Agitation Time}

To determine the effect of agitation time, $50 \mathrm{~mL}\left(\mathrm{C}_{0}=50 \mathrm{mg} / \mathrm{L}\right)$ of aqueous solution was taken in a $250 \mathrm{~mL}$ conical flask. $10 \mathrm{~g} / \mathrm{L}$ of $44 \mu \mathrm{m}$ size biosorbent was added to the aqueous solution in the flask. The conical flask was kept in a temperature dependent orbital shaker at room temperature and shaken for $1 \mathrm{~min}$. Similarly eleven more samples were prepared in $250 \mathrm{~mL}$ conical flasks adding $10 \mathrm{~g} / \mathrm{L}$ of biosorbent in each flask and agitated to different agitation times $(5,10,20,30,40,50,60,70,120,180,240$ and $300 \mathrm{~min}$ ). These samples were filtered separately with Whatman filter papers and the filtrates were analyzed in Atomic Absorption Spectrophotometer (AAS) to obtain the final concentrations of chromium.

\subsubsection{Effect of Biosorbent Size}

$10 \mathrm{~g} / \mathrm{L}$ of $44 \mu \mathrm{m}$ biosorbent size was taken in a $250 \mathrm{~mL}$ conical flask. $50 \mathrm{~mL}$ of aqueous solution was added to the flask and the sample was agitated in an orbital shaker for equilibrium agitation time. The mixture was settled, filtered and filtrate was analyzed in AAS to obtain the final concentration of chromium.

\subsubsection{Effect of Biosorbent Dosage}

$50 \mathrm{~mL}$ of aqueous solution $\left(\mathrm{C}_{0}=20 \mathrm{mg} / \mathrm{L}\right)$ was taken in a $250 \mathrm{~mL}$ conical flask. $10 \mathrm{~g} / \mathrm{L}$ of $44 \mu \mathrm{m}$ size biosorobent was agitated with the above aqueous solution on an orbital shaker for equilibrium agitation time. The mixture was filtered and the filtrate was analyzed in AAS to know the final concentration of chromium in the solution. Four more samples were prepared with different biosorbent dosages of 15, 20, 25 \& $30 \mathrm{~g} / \mathrm{L}$ and the experimental procedure is repeated.

\subsubsection{Effect of $\mathrm{pH}$ of Aqueous Solution}

The effect of $\mathrm{pH}$ on the biosorption of chromium was determined over a $\mathrm{pH}$ range of 1 to 10 . The $\mathrm{pH}$ of the solutions are adjusted by adding required amounts of $0.1 \mathrm{~N} \mathrm{HCl}$ or $0.1 \mathrm{~N} \mathrm{NaOH} .50 \mathrm{~mL}$ of aqueous solution was taken in each of ten conical flasks. The $\mathrm{pH}$ values of aqueous solutions were adjusted to $1,2,3,4,5,6,7,8,9 \& 10$ in separate 250 $\mathrm{mL}$ conical flasks. $20 \mathrm{~g} / \mathrm{L}$ of $44 \mu \mathrm{m}$ size biosorbent was added to each of the conical flasks. The flasks were incubated in shaker at a speed of $160 \mathrm{rpm}$ at $30^{\circ} \mathrm{C}$ for optimum 
agitation time. The sample was allowed to settle, are filtered and analyzed in AAS to obtain final concentration of chromium.

\subsubsection{Effect of Initial Concentration of Chromium in Aqueous Solution}

The effect of initial concentration on biosorption of chromium was determined as follows: $50 \mathrm{~mL}$ of aqueous solutions, each of different chromium concentrations of 5,10 , $20,30,40,50,75,100,125$ and $150 \mathrm{mg} / \mathrm{L}$ were taken in ten $250 \mathrm{~mL}$ conical flasks. $20 \mathrm{~g} / \mathrm{L}$ of $44 \mu \mathrm{m}$ size biosorbent was added to each of the conical flasks. The flasks were agitated on an orbital shaker for equilibrium agitation time at room temperature. The samples were allowed to settle and then filtered separately. The samples thus obtained were analyzed in AAS for the final concentrations of chromium in aqueous solutions.

\subsubsection{Effect of Temperature}

The influence of temperature on biosorption of chromium was determined by keeping biosorbent dosage, $\mathrm{pH}$, and initial chromium ion concentration at optimum values, 50 $\mathrm{mL}$ of aqueous solution is taken in a $250 \mathrm{~mL}$ flask at different temperatures. The flasks were agitated on an orbital shaker for an equilibrium agitation time. The samples were filtered by Whatman filter paper and analyzed in AAS to obtain final concentration of metal.

\subsubsection{Experimental Design for Biosorption Studies}

Once the parameters $\left(\mathrm{pH}, \mathrm{C}_{0}, \mathrm{w}\right.$ and $\left.\mathrm{T}\right)$ having the greatest influence on the responses were identified, the relationship between the parameters and response were determined using central composite design (CCD) under RSM of STATISTICA 6.0 (Stat-Ease Inc., Tulsa, OK, USA) a statistical software package. The CCD design is chosen in this study as it is efficient, flexible and robust. The CCD consists of a complete $2^{n}$ factorial design, where $\mathrm{n}$ is the number of test parameters, $n_{0}$ center points $\left(n_{0} \geq 1\right)$ and two axial points on the axis of each design parameter at a distance of $2^{n / 4}$ from the design center. Hence, the total number of design points is $N=2^{n}+2 n+n_{0}$. Basically the optimization process involves three major steps: 1 ) performing the statistically designed experiments, 2) estimating the coefficients in a mathematical model, and 3) predicting the response and checking the adequacy of the model. For statistical calculations the parameters $X_{i}$ are coded as $X_{i}$ according to Equation (1):

$$
x_{i}=\frac{X_{i}-\bar{x}_{i}}{\Delta x_{i}},(i=1,2,3, \cdots, k)
$$

where $x_{i}$ is dimensionless value of an independent parameter, $X_{i}$ is the real value of an independent parameter, $\bar{x}_{i}$ the is real value of the independent parameter at the center point and $\Delta \mathrm{x}_{i}$ is the step change.

An empirical model was developed to correlate the response to the adsorption process and is based on second-order quadratic model to estimate the response of the dependent parameter:

$$
\begin{aligned}
Y= & b_{0}+b_{1} X_{1}+b_{2} X_{2}+b_{3} X_{3}+b_{4} X_{4}+b_{11} X_{1}^{2}+b_{22} X_{2}{ }^{2}+b_{33} X_{3}^{2}+b_{44} X_{4}^{2}+b_{12} X_{1} X_{2} \\
& +b_{13} X_{1} X_{3}+b_{14} X_{1} X_{4}+b_{23} X_{2} X_{3}+b_{24} X_{2} X_{4}+b_{34} X_{3} X_{4}
\end{aligned}
$$


where $Y$ is predicted response, $X_{1}, X_{2}, X_{3}, X_{4}$ are independent parameters, $b_{0}$ is offset term, $b_{1}, b_{2}, b_{3}, b_{4}$ are linear effects, $b_{11}, b_{22}, b_{33}, b_{44}$ are squared effects and $b_{12}, b_{13}, b_{14}$, $b_{23}, b_{24}, b_{34}$ are interaction terms.

The statistical significance of the coefficient was determined by student's t-test and p-values. The proportion of variance obtained by the model was explained by the multiple coefficient of determination, $\mathrm{R}^{2}$.

In the present study, the \% biosorption of chromium was optimized with four independent parameters $\left(\mathrm{pH}, \mathrm{C}_{0}, \mathrm{w}\right.$ and $\left.\mathrm{T}\right)$. The relationship between the parameters and response (\% biosorption of chromium) were determined using CCD under RSM of STATISTICA 6.0. Thirty experiments were conducted with eight axial points $(\alpha=\sqrt{4})$ and six replications at the center points $\left(n_{0}=6\right)$ according to CCD. Samples taken after the desired incubation period were analyzed using AAS. The regression analyses, graphical analyses and analyses of variance (ANOVA) were done using the STATISTICA-6.0. The statistical significance of the coefficient was determined by student's t-test and p-values. The proportion of variance obtained by the model was explained by the multiple coefficient of determination.

\subsection{Kinetics Studies}

$50 \mathrm{~mL}$ of aqueous solution containing $10 \mathrm{mg} / \mathrm{L}$ of chromium was taken in each of twelve conical flasks. $10 \mathrm{~g} / \mathrm{L}$ of biosorbent having $44 \mu \mathrm{m}$ size was added in each of the flasks. 74 The conical flasks were shaken on an orbital shaker for different time intervals $1,5,10,20,30,40,50,60,70,12740,180,240$ and $300 \mathrm{~min}$. They were then settled, filtered separately and the filtrates were analyzed in AAS to identify the final concentrations of chromium. From these data, order of biosorption was determined.

\subsection{Studies on Isotherms}

In order to determine the isotherms, $50 \mathrm{~mL}$ of known amount of chromium ion concentration is taken in $250 \mathrm{~mL}$ conical flask and to this known amount of biosorbent is added and kept for shaking at $30^{\circ} \mathrm{C}$ at a speed of $160 \mathrm{rpm}$ for optimum time. They are then settled, filtered and the filtrates are analyzed for the final concentrations of metal. The experiment is repeated for different metal ion concentration.

\subsection{Thermodynamic Studies}

The effect of temperature on the biosorption rate was obtained by the following procedure: $50 \mathrm{~mL}$ of aqueous solution $\left(\mathrm{C}_{\mathrm{o}}=20 \mathrm{mg} / \mathrm{L}\right)$ was taken in each of five conical flasks. $20 \mathrm{~g} / \mathrm{L}$ of $44 \mu \mathrm{m}$ size biosorbent was added in each of these flasks. The conical flasks were shaken in an orbital shaker for five different temperatures $(283,293,303,313$ and $323 \mathrm{~K})$. These samples were settled and filtered separately. The final chromium concentrations of the filtrates were determined using AAS. From these data, the enthalpy change of adsorption $(\Delta \mathrm{H})$, entropy change of adsorption $(\Delta \mathrm{S})$ and Gibbs free energy change $(\Delta \mathrm{G})$ were evaluated.

The experimental conditions for biosorption of chromium onto Gracilaria corticata powder are given in Table 1. 
Table 1. Experimental conditions for biosorption of chromium.

\begin{tabular}{ccc}
\hline S.No. & Parameter & Values Investigated \\
\hline 1 & Agitation time, $\mathrm{t}, \mathrm{min}$ & $1,5,10,20,30,40,50,60,90,120,180,240 \& 300$ \\
2 & Biosorbent size, $\mathrm{d}_{\mathrm{p}}, \mu \mathrm{m}$ & $44.72 \& 104$ \\
3 & Initial Biosorbent dosage, $\mathrm{w}, \mathrm{g} / \mathrm{L}$ & $10,15,20,25 \& 30$ \\
4 & $\mathrm{pH}$ of the aqueous solution & $1,2,3,4,5,6,7,8,9 \& 10$ \\
5 & Initial metal concentration, $\mathrm{C}_{\mathrm{o}}, \mathrm{mg} / \mathrm{L}$ & $5,10,20,30,40,50,75,100,125 \& 150$ \\
6 & Temperature, $\mathrm{K}$ & $283,293,303,313 \& 323$ \\
\hline
\end{tabular}

\section{Results and Discussions}

\subsection{Equilibrium Studies on Biosorption of Chromium}

\subsubsection{Effect of Agitation Time}

The effect of agitation time for the biosorption of chromium on Gracilaria corticatapowder was shown in Figure 1. The data obtained from the chromium biosorption showed that a contact time of $240 \mathrm{~min}$ to achieve an optimum biosorption and there was no significant change in concentration of the chromium ion with further increase in contact time [11]. The percentage biosorption of chromium attained at $240 \mathrm{~min}$ was 70.97\%. As shown in Figure 1, the biosorption process took place in two stages. The first stage was rapid, where about $60 \%$ was completed within first $50 \mathrm{~min}$. The second stage represented a slower progressive adsorption. The rapid initial biosorption may be attributed to the accumulation of metals on to the surface of biosorbent, due to its large surface area. With the progressive occupation of these sites, process became slower in the second stage.

\subsubsection{Effect of Biosorbent Size}

The percentage biosorption of chromium is increased from $70.09 \%(1.7522 \mathrm{mg} / \mathrm{g})$ to $75.59 \%(1.8897 \mathrm{mg} / \mathrm{g})$ as the biosorbent size decreases from 104 to $44 \mu \mathrm{m}$ with an increase in biosorbent dosage from $10 \mathrm{~g} / \mathrm{L}$ to $25 \mathrm{~g} / \mathrm{L}$, at $303 \mathrm{~K}$ for $50 \mathrm{mg} / \mathrm{L}$ of chromium initial concentration. (Figure 2) With an increase in biosorbent sizes, surface area of the biosorbent increases, thereby the number of active sites available on the biosorbent is better exposed to the biosorbate. Similar results were noticed by other researchers [12].

\subsubsection{Effect of Biosorbent Dosage}

Biosorbent dose had a very profound effect on Cr (VI) removal. Biosorption experiments were carried out at varying biosorbent dosages $(0.5-2.5 \mathrm{gm} / 50 \mathrm{ml})$. The percentage removal of chromium is drawn against biosorbent dosage for $44 \mu \mathrm{m}$ in Figure 3. The biosorption of chromium increases from $70.97 \%$ to $75.93 \%$, with an increase in biosorbent dosage from 10 to $30 \mathrm{~g} / \mathrm{L}$ [11] [13]. The phenomenon of increase in percentage removal of $\mathrm{Cr}(\mathrm{VI})$ with increase in biosorbent dose up to certain level and beyond that more or less constant removal can be observed as with increase in biosorbent dose, more and more binding sites become available for complexation of $\mathrm{Cr}$ (VI) ions and this increased the rate of adsorption. However very slow increase in removal beyond an 
optimum dose may be attributed to attainment of equilibrium between biosorbate and biosorbent at the existing operating conditions [13]. Higher biosorbent dose cause screening effect of dense outer layer of cells, blocking the binding sites from metal ions, was resulting in lower metal removal per unit biosorbent [14].

\subsubsection{Effect of $\mathrm{pH}$}

The biosorption of cations and anions on biosorbent totally depends upon $\mathrm{pH}$ of aqueous solution. The effect of $\mathrm{pH}$ on percentage biosorption was investigated and shown in Figure 4. It reveals that percentage biosorption increased from $69.12 \%$ to

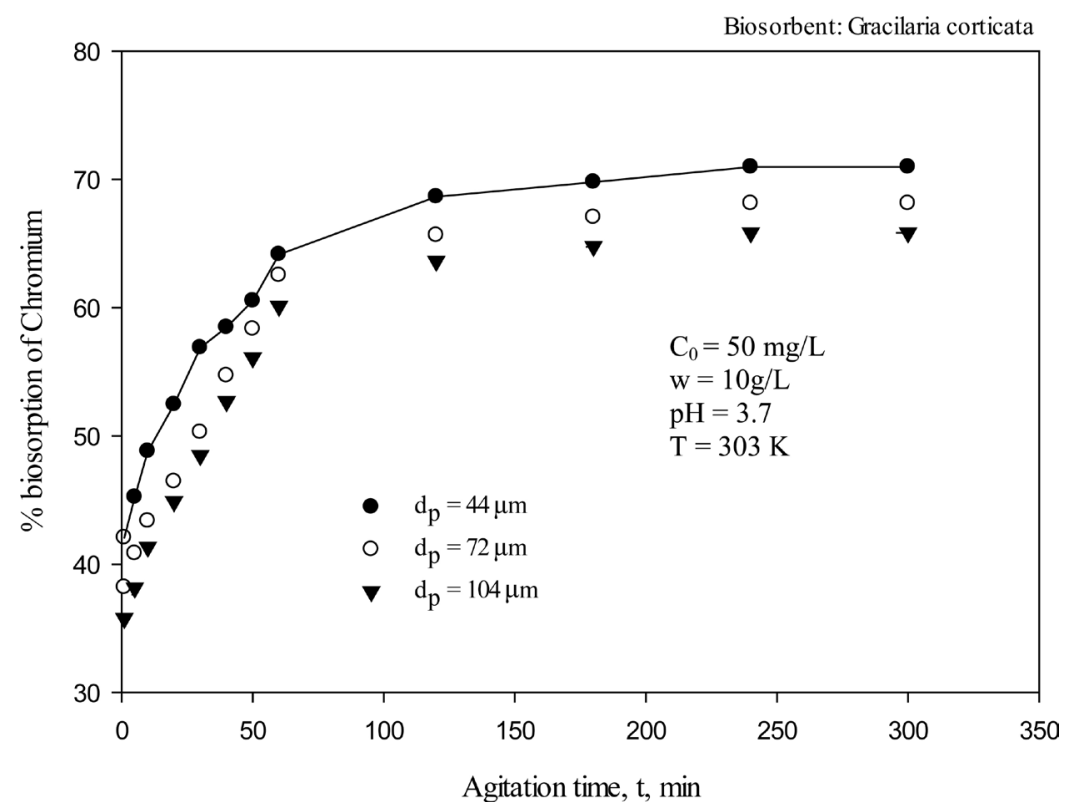

Figure 1. Effect of agitation time on chromium biosorption.

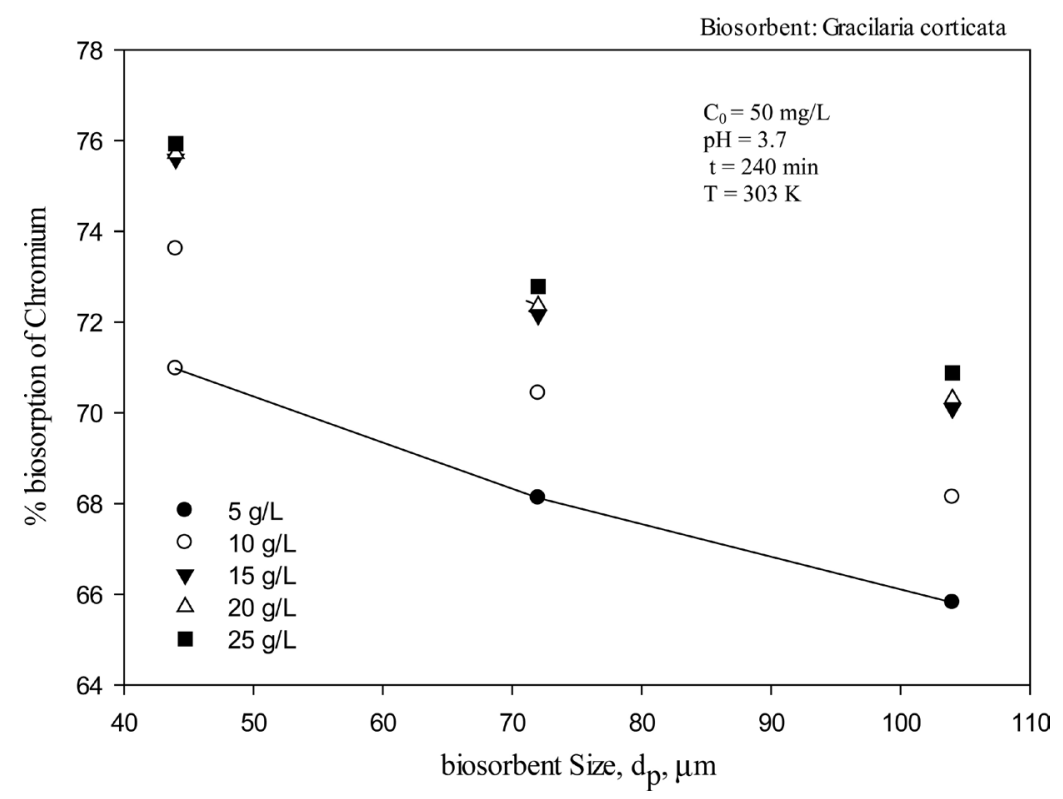

Figure 2. Effect of biosorbent size on chromium biosorption. 


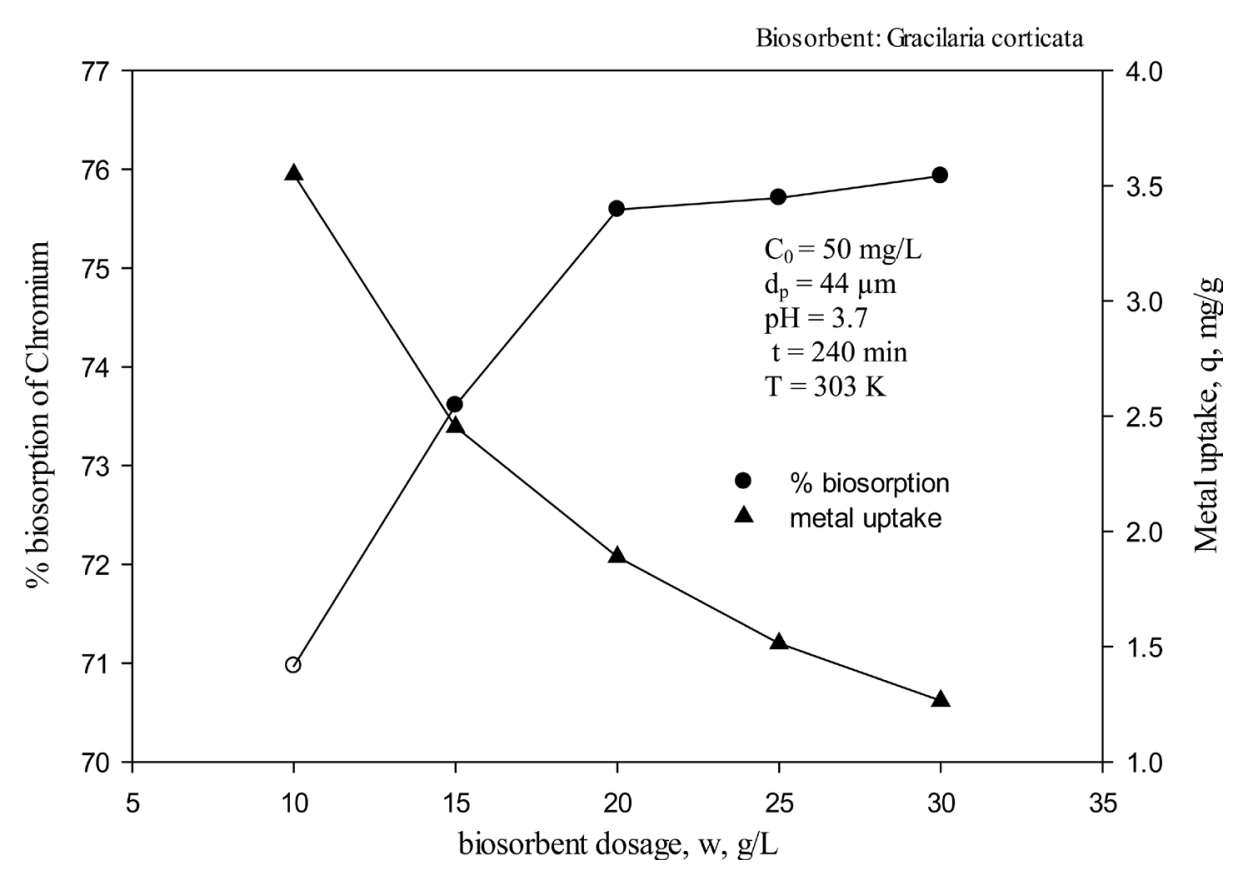

Figure 3. Influence of biosorbent dosage on chromium biosorption.

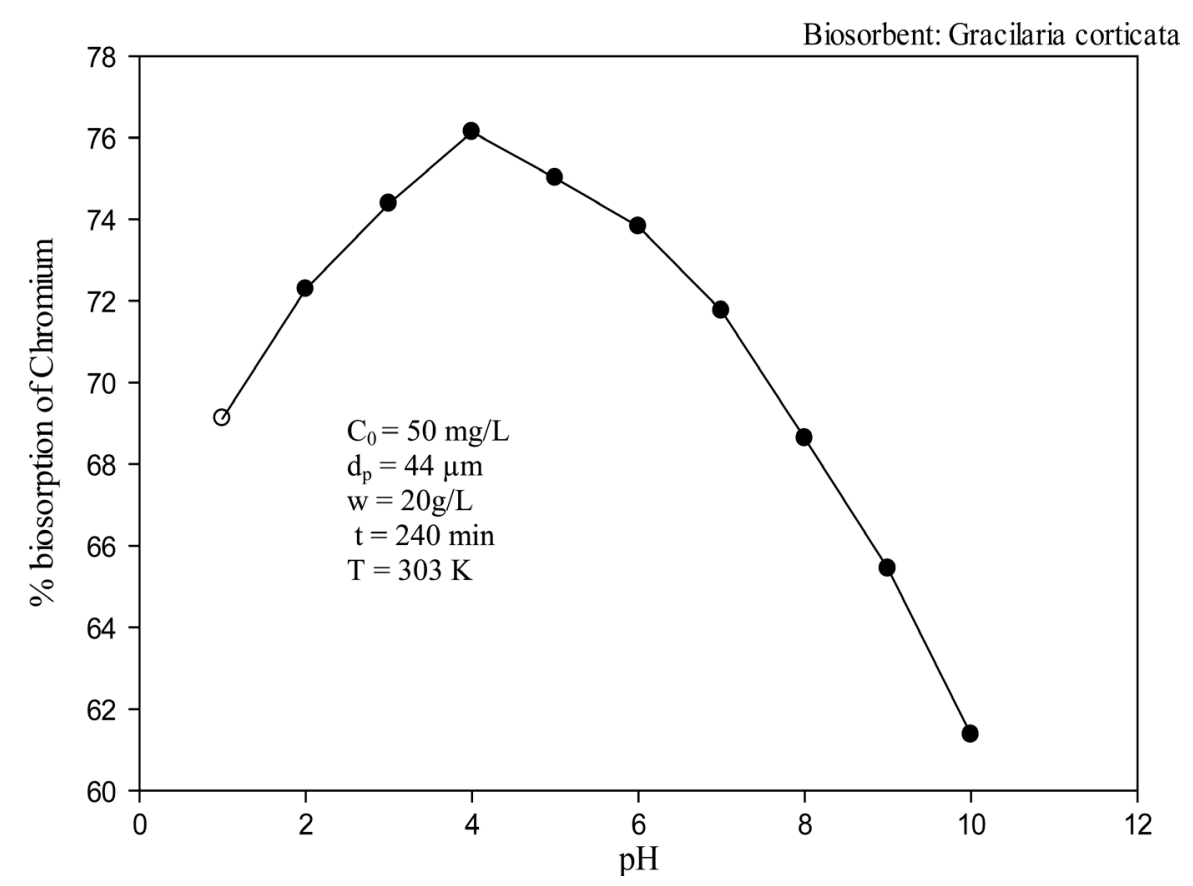

Figure 4. Effect of $\mathrm{pH}$ of aqueous solution on \% biosorption of chromium.

$76.14 \%$ as $\mathrm{pH}$ is increased from 1 to 4 and then decreased beyond $\mathrm{pH}$ value of 4 reaching $61.4 \%$ for $\mathrm{pH}$ value of 10 . The increased biosorption with $\mathrm{pH}$ may be due to more of negatively charged groups in biomass surface capable of binding positively charged metal ions. Decrease in biosorption at higher $\mathrm{pH}(\mathrm{pH}>4)$ may be due to the formation of soluble hydroxylated complexes of the metal ions and their competition with the active sites, and as a consequence, the retention would decrease [8]. 


\subsubsection{Effect of Initial Chromium Concentration}

Figure 5 shows the effect of initial concentration of chromium in aqueous solution on the percentage biosorption of chromium. The percentage biosorption of chromium decreased from $89.37 \%$ to $56.23 \%$ as the initial chromium concentration increased from 5 to $150 \mathrm{mg} / \mathrm{L}$. The decrease in percentage biosorption may be attributed due to lack of sufficient surface area to accumulate much more metal available in the solution [15] [16]. The chromium uptake increased from 0.2234 to $4.2172 \mathrm{mg} / \mathrm{g}$, as the initial chromium concentration increased from 5 to $150 \mathrm{mg} / \mathrm{L}$.

\subsubsection{Effect of Temperature}

The effect of temperature on biosorption of chromium was studied from 283 to $323 \mathrm{~K}$ and was depicted in Figure 6. The results show that for the initial concentration of $\left(\mathrm{C}_{0}\right)$ $20 \mathrm{mg} / \mathrm{L}$, the $\%$ biosorption increased from $79.31 \%$ to $91.44 \%$ as temperature increased from 283 to $323 \mathrm{~K}$ [17].

\subsection{Optimization Using Response Surface Methodology (RSM)}

Optimization of the Selected Parameters Using CCD

The following experiments were carried out to study the parameters in such a range so that reasonable percentage biosorption of chromium would be achieved within that range. From the results of preliminary experimental runs, the four parameters $(\mathrm{pH}$, initial chromium concentration, biosorbent dosage and temperature of the aqueous solution) have been identified as the potential parameters for the percentage biosorption of chromium. A summary of the independent parameters and their range and levels were presented in Table 2.

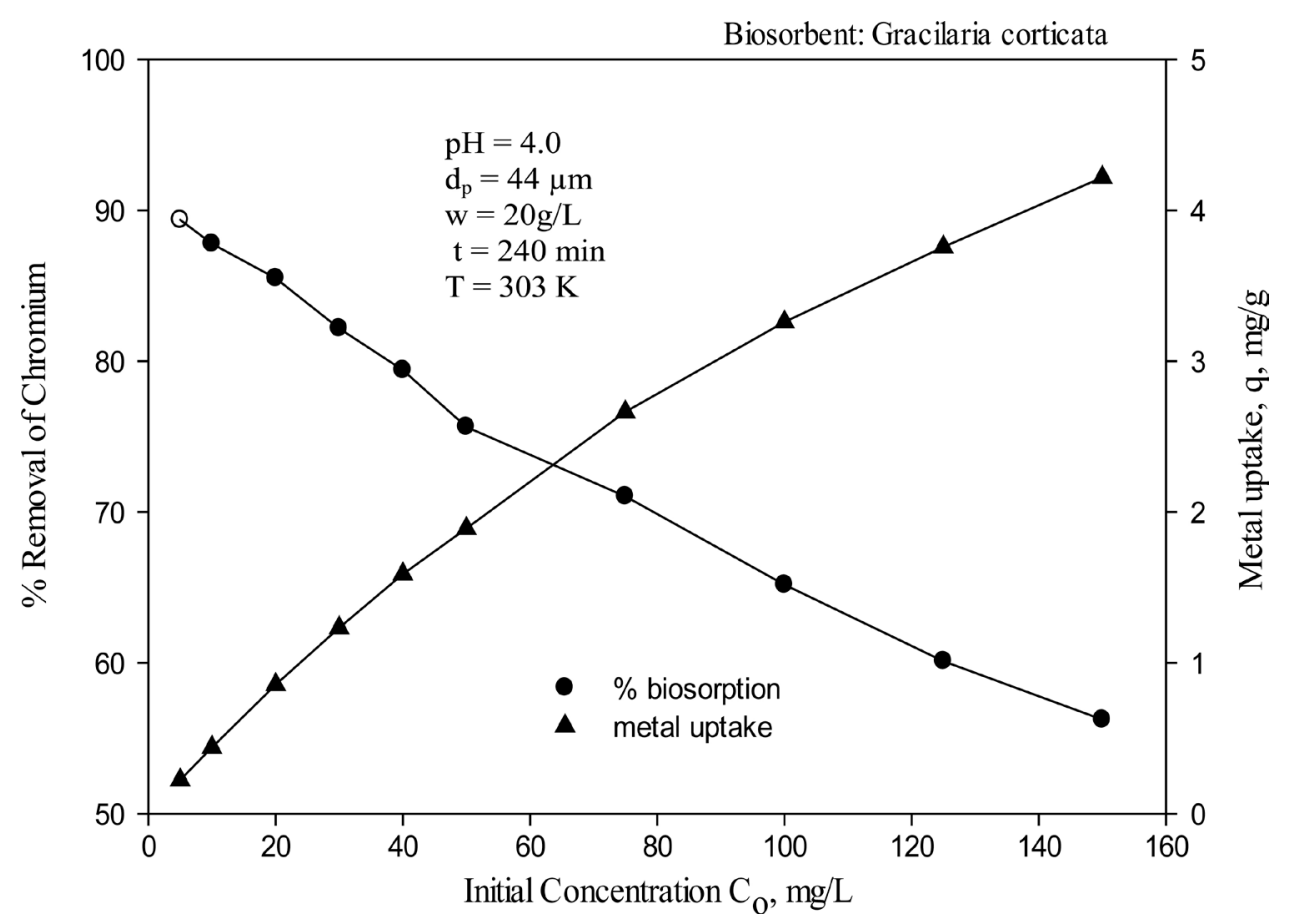

Figure 5. Variation of initial concentration on chromium biosorption. 


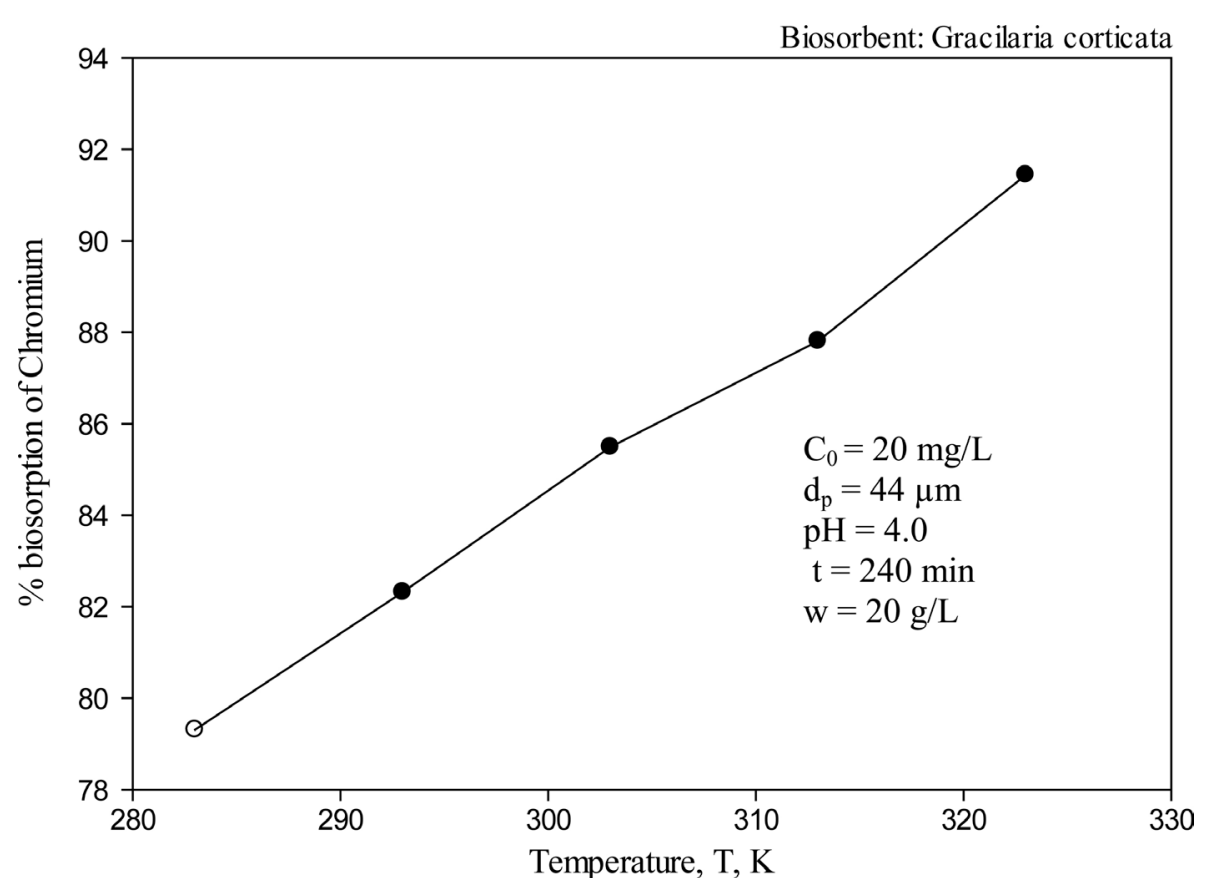

Figure 6. Effect of temperature on chromium biosorption.

Table 2. Experimental range and levels of the independent parameters.

\begin{tabular}{cccccc}
\hline & \multicolumn{5}{c}{ Range and level } \\
\cline { 2 - 5 } Independent parameters & $\mathbf{2}$ & $-\mathbf{1}$ & $\mathbf{0}$ & $\mathbf{+ 1}$ & $\mathbf{+ 2}$ \\
\hline $\mathrm{pH}\left(X_{1}\right)$ & 2 & 3 & 4 & 5 & 6 \\
Initial Cr concentration $\left(X_{2}\right), \mathrm{mg} / \mathrm{L}$ & 10 & 15 & 20 & 25 & 30 \\
Biosorbent dosage $\left(X_{3}\right), \mathrm{g} / \mathrm{L}$ & 10 & 15 & 20 & 25 & 30 \\
Temperature $\left(X_{4}\right), \mathrm{K}$ & 283 & 293 & 303 & 313 & 323 \\
\hline
\end{tabular}

A $2^{4}$-factorial central composite experimental design, with eight axial points ( $\alpha=$ $\sqrt{4}$ ) and six replications at the center points $\left(n_{0}=6\right)$ leading to a total number of 30 experiments (Table 3 ) was employed for the optimization of the parameters. The calculated regression equation for the optimization of medium constituents showed that percentage removal of chromium $(Y)$ was function of the $\mathrm{pH}\left(X_{1}\right)$, initial chromium concentration $\left(X_{2}\right)$, biosorption dosage $\left(X_{3}\right)$ and temperature $\left(X_{4}\right)$.

Multiple regression analysis of the experimental data resulted in the following equation for the biosorption of chromium:

$$
\begin{aligned}
Y= & -284.636+13.021 X_{1}+2.589 X_{2}+4.169 X_{3}+1.799 X_{4}-1.048 X_{1}^{2}-0.051 X_{2}^{2} \\
& -0.041 X_{3}^{2}-0.002 X_{4}^{2}+0.052 X_{1} X_{2}-0.044 X_{1} X_{3}-0.017 X_{1} X_{4}+0.001 X_{2} X_{3} \\
& -0.003 X_{2} X_{4}-0.008 X_{3} X_{4}
\end{aligned}
$$

The predicted percentage biosorption of chromium resulted from Equation (3) are in close agreement with the experimental values as evident from last column of Table 3. For quadratic models, the optimum point can be characterized as maximum, minimum, or saddle. 
Table 3. CCD matrix showing coded and real values along with the experimental values for percentage biosorption of chromium.

\begin{tabular}{|c|c|c|c|c|c|c|c|c|c|c|}
\hline \multirow{2}{*}{$\begin{array}{l}\text { Run } \\
\text { no. }\end{array}$} & \multicolumn{4}{|c|}{ Coded values } & \multicolumn{4}{|c|}{ Real values } & \multicolumn{2}{|c|}{$\%$ biosorption of chromium } \\
\hline & $x_{1}$ & $x_{2}$ & $x_{3}$ & $x_{4}$ & $X_{1}$ & $X_{2}$ & $X_{3}$ & $X_{4}$ & Experimental & Predicted \\
\hline 1 & -1 & -1 & -1 & -1 & 3 & 15 & 15 & 293 & 80.960 & 80.936 \\
\hline 2 & -1 & -1 & -1 & 1 & 3 & 15 & 15 & 313 & 82.960 & 82.842 \\
\hline 3 & -1 & -1 & 1 & -1 & 3 & 15 & 25 & 293 & 82.720 & 82.655 \\
\hline 4 & -1 & -1 & 1 & 1 & 3 & 15 & 25 & 313 & 82.980 & 83.034 \\
\hline 5 & -1 & 1 & -1 & -1 & 3 & 25 & 15 & 293 & 80.360 & 80.234 \\
\hline 6 & -1 & 1 & -1 & 1 & 3 & 25 & 15 & 313 & 81.620 & 81.593 \\
\hline 7 & -1 & 1 & 1 & -1 & 3 & 25 & 25 & 293 & 81.970 & 82.066 \\
\hline 8 & -1 & 1 & 1 & 1 & 3 & 25 & 25 & 313 & 81.810 & 81.897 \\
\hline 9 & 1 & -1 & -1 & -1 & 5 & 15 & 15 & 293 & 80.870 & 80.745 \\
\hline 10 & 1 & -1 & -1 & 1 & 5 & 15 & 15 & 313 & 82.060 & 81.989 \\
\hline 11 & 1 & -1 & 1 & -1 & 5 & 15 & 25 & 293 & 81.540 & 81.593 \\
\hline 12 & 1 & -1 & 1 & 1 & 5 & 15 & 25 & 313 & 81.220 & 81.309 \\
\hline 13 & 1 & 1 & -1 & -1 & 5 & 25 & 15 & 293 & 81.110 & 81.081 \\
\hline 14 & 1 & 1 & -1 & 1 & 5 & 25 & 15 & 313 & 81.750 & 81.777 \\
\hline 15 & 1 & 1 & 1 & -1 & 5 & 25 & 25 & 293 & 81.960 & 82.040 \\
\hline 16 & 1 & 1 & 1 & 1 & 5 & 25 & 25 & 313 & 81.160 & 81.209 \\
\hline 17 & -2 & 0 & 0 & 0 & 2 & 20 & 20 & 303 & 81.470 & 81.525 \\
\hline 18 & 2 & 0 & 0 & 0 & 6 & 20 & 20 & 303 & 80.690 & 80.647 \\
\hline 19 & 0 & -2 & 0 & 0 & 4 & 10 & 20 & 303 & 80.510 & 80.607 \\
\hline 20 & 0 & 2 & 0 & 0 & 4 & 30 & 20 & 303 & 79.890 & 79.805 \\
\hline 21 & 0 & 0 & -2 & 0 & 4 & 20 & 10 & 303 & 80.350 & 80.590 \\
\hline 22 & 0 & 0 & 2 & 0 & 4 & 20 & 30 & 303 & 81.970 & 81.742 \\
\hline 23 & 0 & 0 & 0 & -2 & 4 & 20 & 20 & 283 & 83.690 & 83.754 \\
\hline 24 & 0 & 0 & 0 & 2 & 4 & 20 & 20 & 323 & 84.880 & 84.829 \\
\hline 25 & 0 & 0 & 0 & 0 & 4 & 20 & 20 & 303 & 85.280 & 85.280 \\
\hline 26 & 0 & 0 & 0 & 0 & 4 & 20 & 20 & 303 & 85.280 & 85.280 \\
\hline 27 & 0 & 0 & 0 & 0 & 4 & 20 & 20 & 303 & 85.280 & 85.280 \\
\hline 28 & 0 & 0 & 0 & 0 & 4 & 20 & 20 & 303 & 85.280 & 85.280 \\
\hline 29 & 0 & 0 & 0 & 0 & 4 & 20 & 20 & 303 & 85.280 & 85.280 \\
\hline 30 & 0 & 0 & 0 & 0 & 4 & 20 & 20 & 303 & 85.280 & 85.280 \\
\hline
\end{tabular}

The coefficients of the regression model were calculated and listed in Table 4. They contain one block term, four linear, four quadratic and six interaction terms. The significance of each coefficient was determined by student's $t$-test and $p$-values and listed in 
Table 4. The larger the magnitude of the $t$-value and smaller the $p$-value, the more significant was the corresponding coefficient. This implies that all the linear terms $(\mathrm{pH}$, initial concentration, biosorbent dosage and temperature) and quadratic effects of $\mathrm{pH}$, initial concentration, biosorbent dosage and temperature were highly significant as is evident from their respective $p$-values. The interaction effects of $\mathrm{pH}$ and initial concentration, $\mathrm{pH}$ and biosorbent dosage, $\mathrm{pH}$ and temperature, biosorbent dosage and temperature were found to be significant $(p \leq 0.05)$. The remaining two interaction effects i.e. initial concentration and biosorbent dosage, initial concentration and temperature were found to be insignificant $(p>0.05)$ which are presented in Table 4.

The parity plot (Figure 7 ) showed a satisfactory correlation between the experimental and predicted values for the percentage removal of chromium indicating good agreement of model data with the experimental data. The results of the sum of squares of response surface model, fitting in the form of ANOVA were shown in Table 5. The Fisher variance ratio, the $F$-value $\left(=S_{r}^{2} / S_{e}^{2}\right)$, is a statistically valid measure to test the significance and adequacy of the model.

The greater the $F$-value above unity, it is more certain that the factors adequately explain the variation in the data about its mean, and the estimated factor effects are real. The ANOVA of the regression model demonstrated that the model was highly significant, as is evident from the Fisher's $F$-test $\left(F_{\text {model }}=671.1476\right)$ and a very low probability value $\left(P_{\text {model }}>F=0.000000\right)$.

The correlation coefficient $\left(R^{2}\right)$ provides a measure of the models variability in the Table 4. Coefficients, $t$-statistics and significance probability of the model.

\begin{tabular}{ccccc}
\hline Terms & Regression coefficient & Standard error of the coefficient & t-value & $P$-value \\
\hline Constant & -284.636 & 23.05693 & -12.3449 & $0.000000^{\mathrm{a}}$ \\
$X_{1}$ & 13.021 & 0.98283 & 13.2488 & $0.000000^{\mathrm{a}}$ \\
$X_{2}$ & 2.589 & 0.19657 & 13.1705 & $0.000000^{\mathrm{a}}$ \\
$X_{3}$ & 4.169 & 0.19657 & 21.2103 & $0.000000^{\mathrm{a}}$ \\
$X_{4}$ & 1.799 & 0.14635 & 12.2897 & $0.000000^{\mathrm{a}}$ \\
$X_{1}{ }^{*} X_{1}$ & -1.048 & 0.02388 & -43.9039 & $0.000000^{\mathrm{a}}$ \\
$X_{2}{ }^{*} X_{2}$ & -0.051 & 0.00096 & -53.1165 & $0.000000^{\mathrm{a}}$ \\
$X_{3}{ }^{*} X_{3}$ & -0.041 & 0.00096 & -43.066 & $0.000000^{\mathrm{a}}$ \\
$X_{4}{ }^{*} X_{4}$ & -0.002 & 0.00024 & -10.3511 & $0.000000^{\mathrm{a}}$ \\
$X_{1}{ }^{*} X_{2}$ & 0.052 & 0.00625 & 8.2956 & $0.000001^{\mathrm{a}}$ \\
$X_{1}{ }^{*} X_{3}$ & -0.044 & 0.00625 & -6.9763 & $0.000004^{\mathrm{a}}$ \\
$X_{1}{ }^{*} X_{4}$ & -0.017 & 0.00313 & -5.2972 & $0.000090^{\mathrm{a}}$ \\
$X_{2}{ }^{*} X_{3}$ & 0.001 & 0.00125 & 0.995 & 0.382589 \\
$X_{2}{ }^{*} X_{4}$ & -0.003 & 0.00063 & -4.3777 & 0.000541 \\
$X_{3}{ }^{*} X_{4}$ & -0.008 & 0.00063 & -12.2135 & $0.000000^{\mathrm{a}}$ \\
\hline
\end{tabular}

${ }^{\mathrm{a}}$ Significant $(p \leq 0.05)$. 


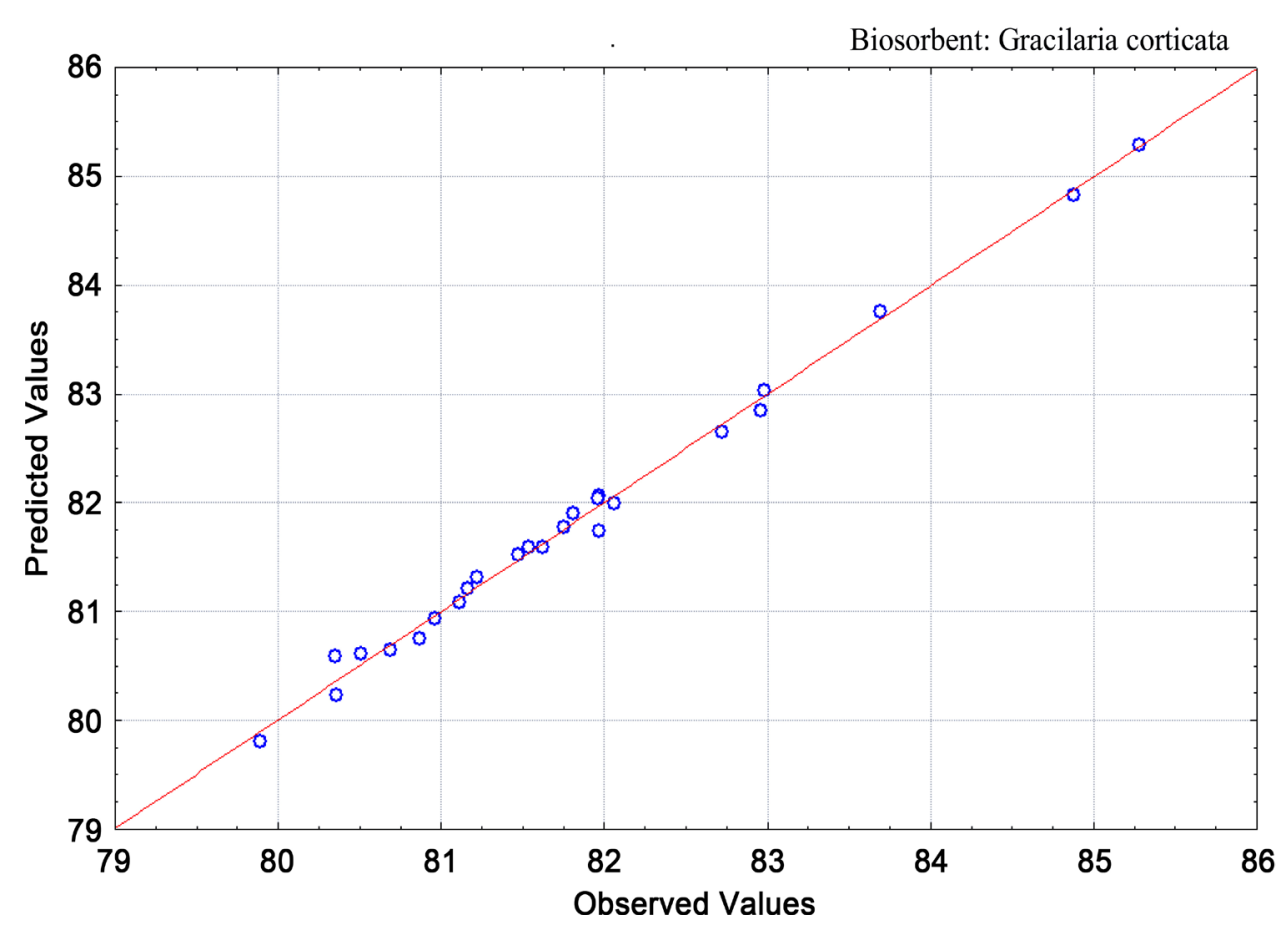

Figure 7. Parity plot showing the distribution of experimental vs. predicted values of percentage biosorption of chromium.

Table 5. ANOVA for the entire quadratic model.

\begin{tabular}{cccccc}
\hline $\begin{array}{c}\text { Source of } \\
\text { Variation }\end{array}$ & $\begin{array}{c}\text { Sum of Squares } \\
(\text { SS })\end{array}$ & $\begin{array}{c}\text { Degree of } \\
\text { Freedom (DF) }\end{array}$ & $\begin{array}{c}\text { Mean Squares } \\
(\mathrm{MS})\end{array}$ & $\boldsymbol{F}$-value & Probe $>\boldsymbol{F}$ \\
\hline Model & 91.92909 & 14 & 104.9675 & 671.1476 & 0.000000 \\
Error & 0.23463 & 15 & 0.1564 & & \\
Total & 92.16372 & 29 & & & \\
\hline
\end{tabular}

observed response values. The closer the $R^{2}$ value to 1 , the stronger the model is and it predicts the response better. In this present study, the value of the correlation coefficient $\left(R^{2}=0.989\right)$ indicated that $98.90 \%$ of the variability in the response could be explained by the model. In addition, the value of the adjusted correlation coefficient (adj $\left.R^{2}=0.9856\right)$ was also very high to advocate for high significance of the model. A higher value of the correlation coefficient $(R=0.989)$ justified an excellent correlation between the independent parameters.

The response surface contour plots of percentage biosorption of chromium versus the interactive effect of $\mathrm{pH}$, initial chromium concentration, biosorbent dosage and temperature of the aqueous solution were shown in the Figures 8(a)-(f). Each contour plot represents a number of combinations of two test parameters with the other parameters maintained at zero levels. The maximum percentage biosorption of chromium is indicated by the surface confined in the smallest curve (circular or elliptical) of the contour plot.

The optimal set of conditions for maximum percentage biosorption of chromium is 
$\mathrm{pH}$ of the aqueous solution $=3.827$

Initial chromium concentration $=19.35 \mathrm{mg} / \mathrm{L}$

Biosorbent dosage $=20.2233 \mathrm{~g} / \mathrm{L}$

Temperature $=306.02 \mathrm{~K}$

The extent of biosorption of chromium $=85.39 \%$

Biosorbent: Gracilaria corticata

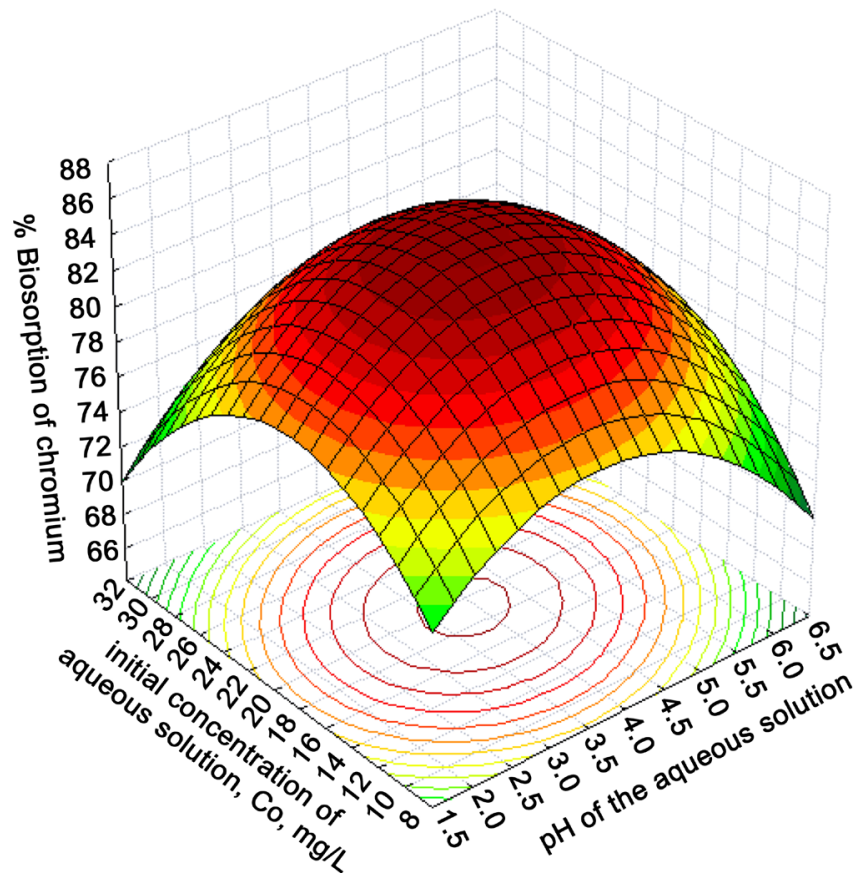

84
82
80
78
76
74
72
70

(a)

Biosorbent: Gracilaria corticata

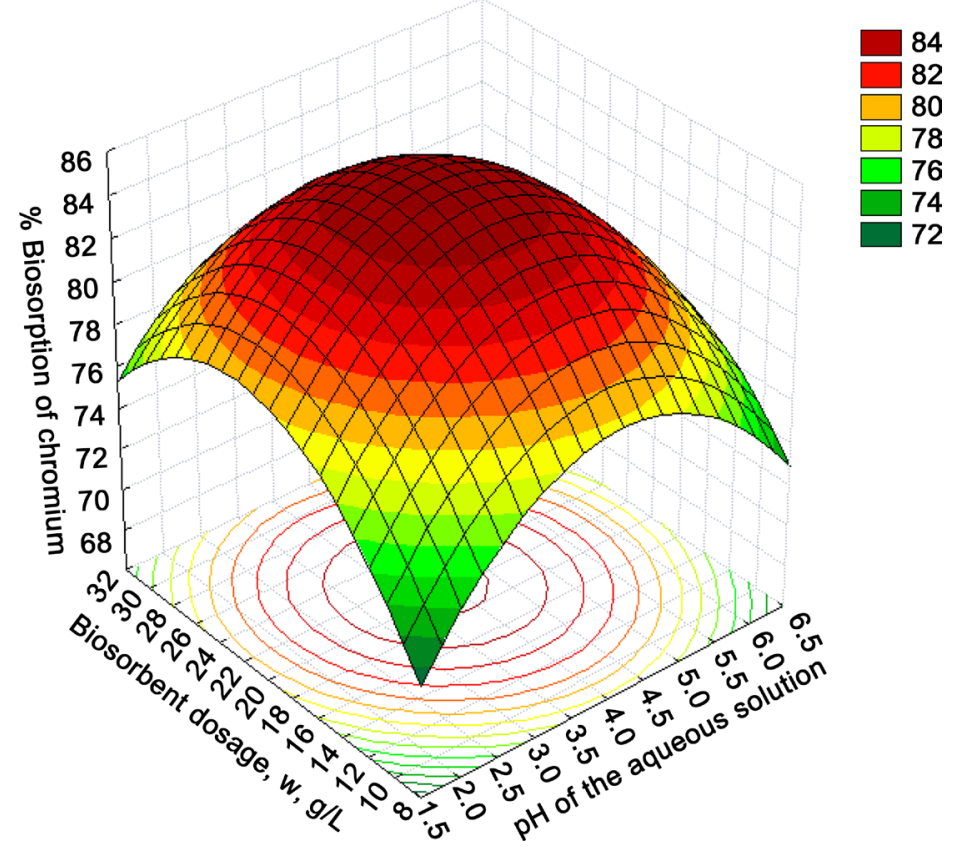

(b) 


\section{Biosorbent: Gracilaria corticata}
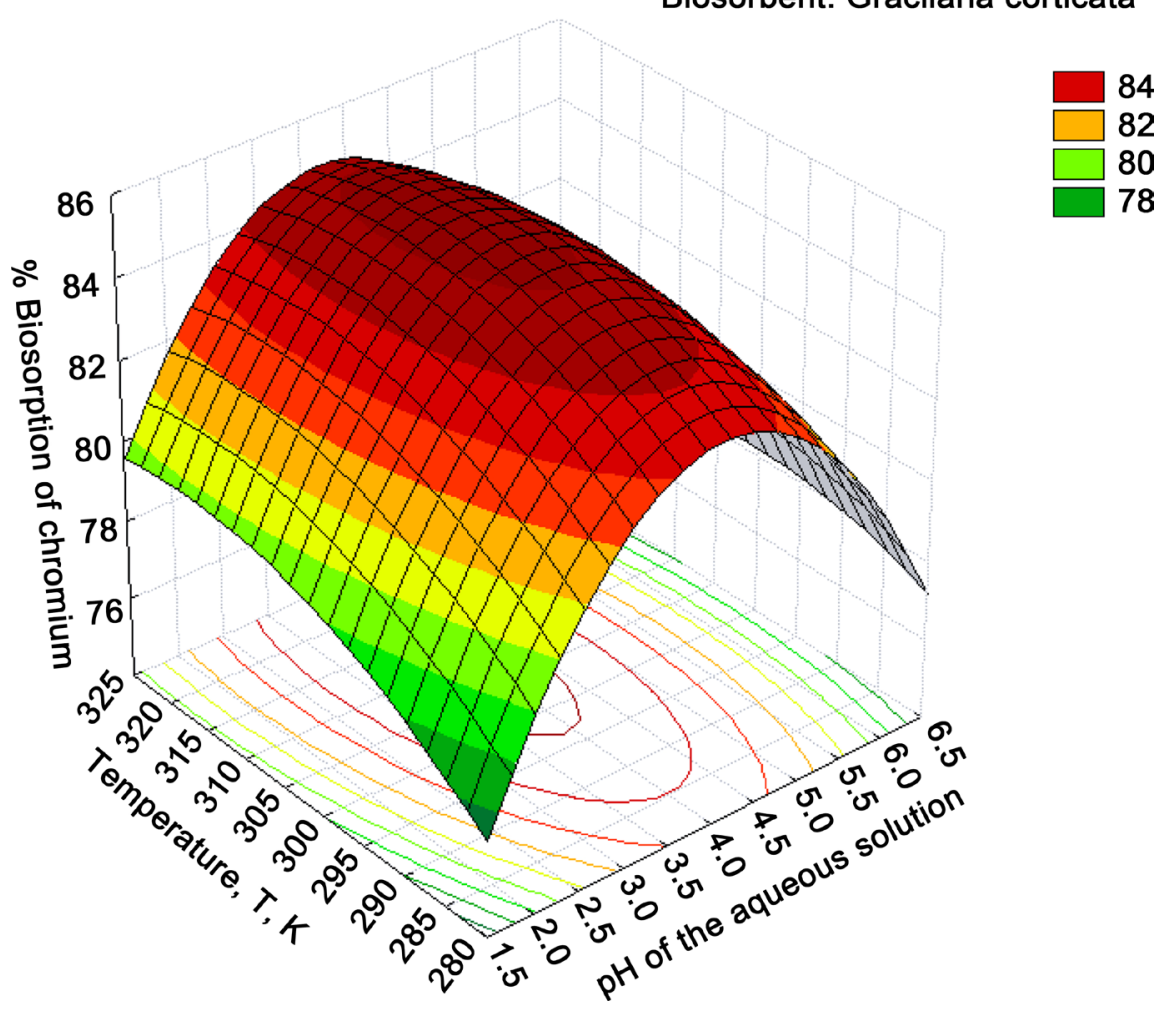

(c)

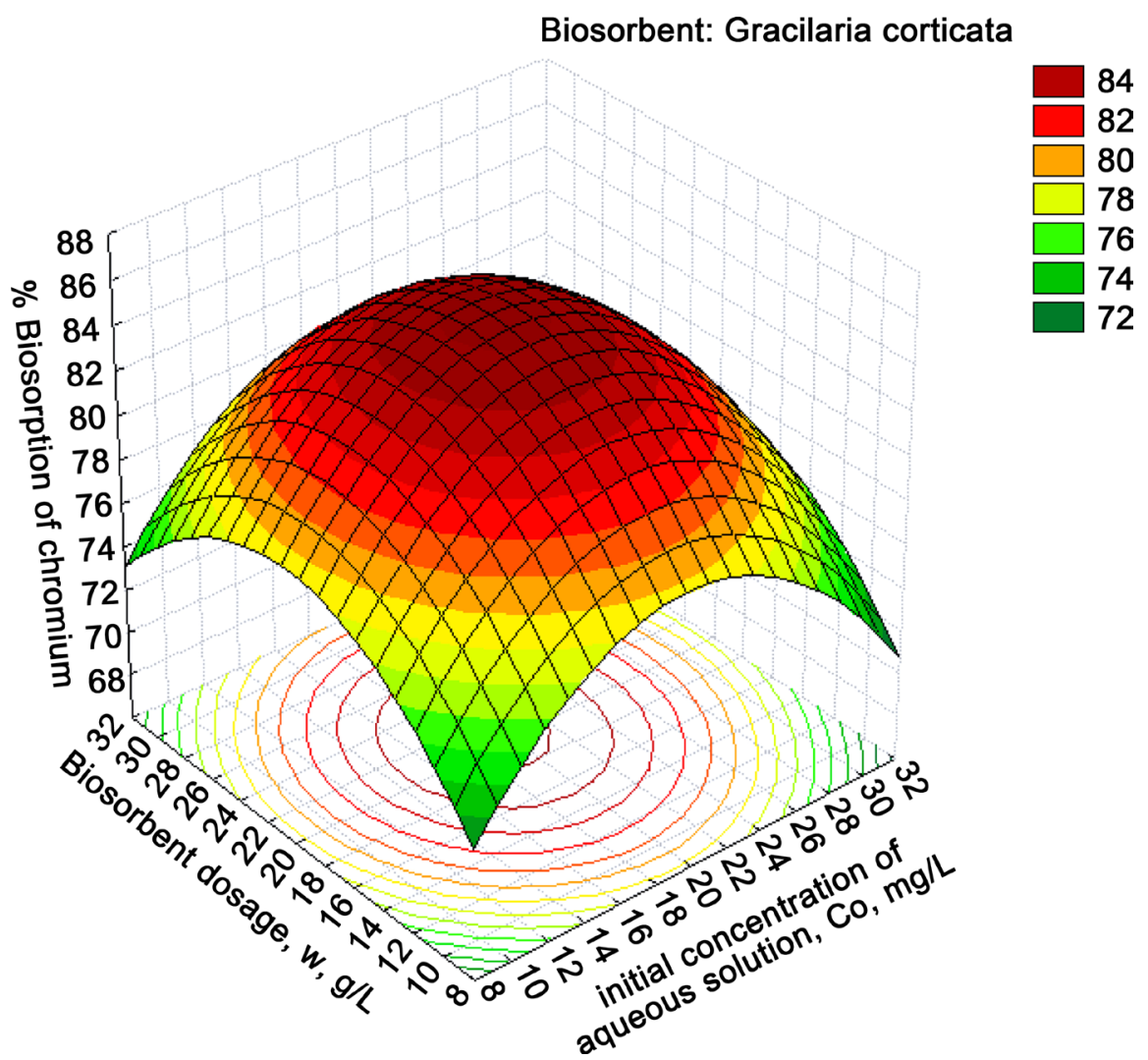

(d) 


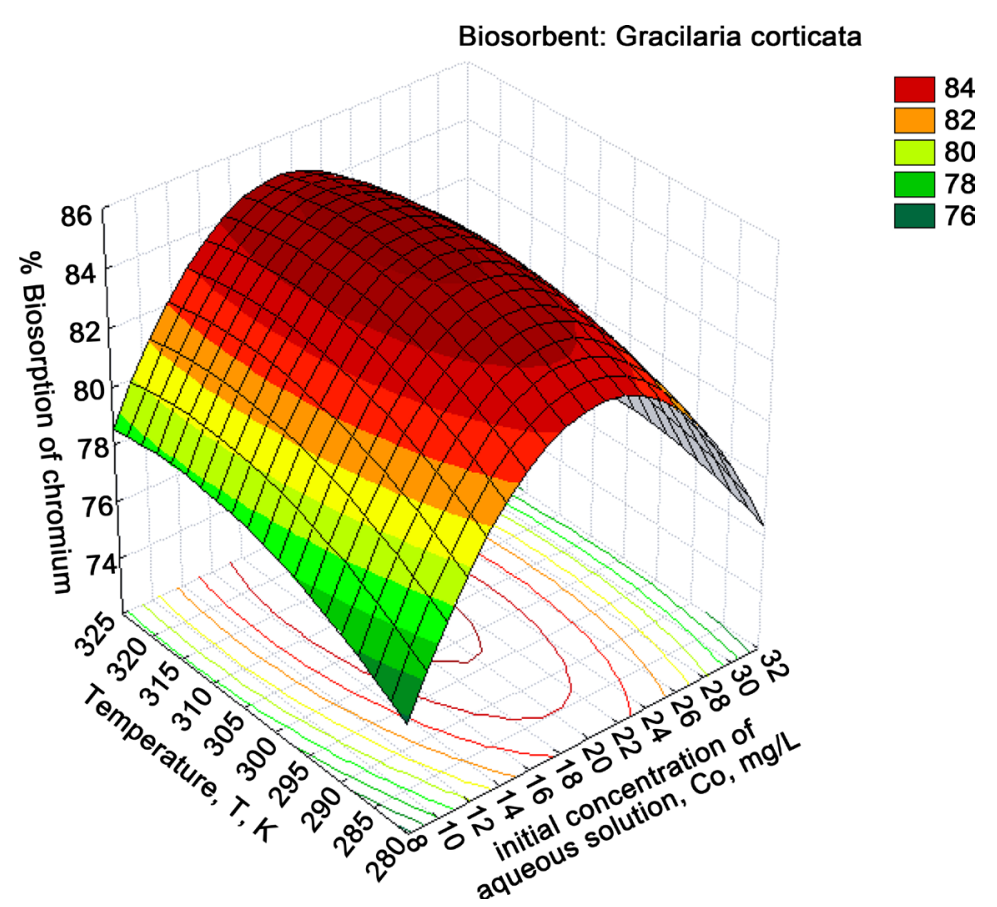

(e)

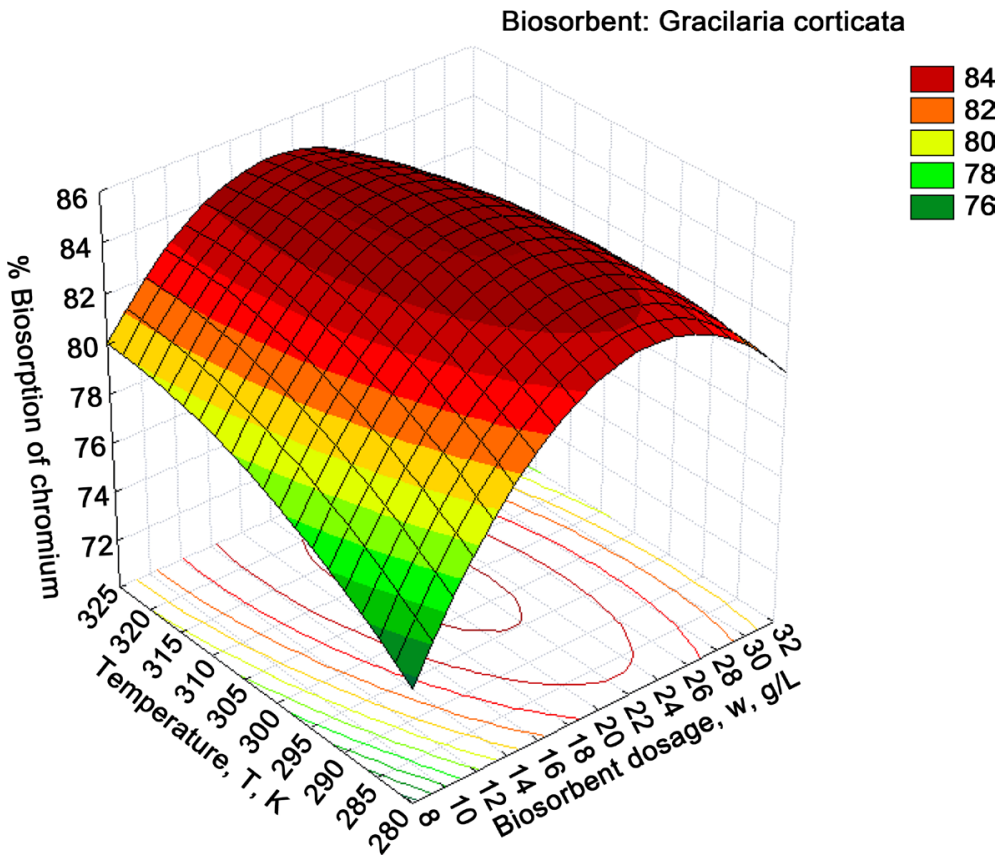

(f)

Figure 8. (a) Response and contour plot of the effects of $\mathrm{pH}$ and initial concentration of chromium on percentage biosorption of chromium; (b) Response and contour plot of the effects of $\mathrm{pH}$ and biosorbent dosage on percentage biosorption of chromium; (c) Response and contour plot of the effects of $\mathrm{pH}$ and temperature on percentage biosorption of chromium; (d) Response and contour plot of the effects of initial concentration of chromium and biosorbent dosage on percentage biosorption of chromium; (e) Response and contour plot of the effects of initial concentration of chromium and temperature on percentage biosorption of chromium; (f) Response and contour plot of the effects of biosorbent dosage and temperature on percentage biosorption of chromium. 
It is evident that experimental values of \% biosorption are in close agreement with that values predicted by Central Composite Design. Experiments are conducted in triplicate with the above predicted optimal set of conditions and the \% biosorption of chromium is $85.49 \%$, which is closer to the predicted \% biosorption.

The experimental and predicted \% biosorption of chromium at the optimum levels of process parameters were shown in Table 6.

\subsection{Kinetic Studies}

The biosorption kinetics is one of the most important data in order to understand the mechanism of biosorption and to assess the performance of the biosorbents [18]. The pseudo-first order, second order and intra-particle diffusion kinetic models were used to analyze the data of $\mathrm{Cr}$ (VI) ions biosorption on to Gracilaria corticata powder.

\subsubsection{Pseudo-First-Order Kinetic Model}

The pseudo first order kinetic equation can be expressed as:

$$
\frac{\mathrm{d} q}{\mathrm{~d} t}=k_{1}\left(q_{e}-q_{t}\right)
$$

where " $q_{e}$ " is the amount of solute adsorbed at equilibrium per unit mass of adsorbent (mg. $\mathrm{g}^{-1}$ ), " $q_{t}$ " is the amount of solute adsorbed at any given time " $t$ " and " $k_{1}$ " is the rate constant. By using the boundary conditions and simplifying, the Equation (4) becomes

$$
\ln \left(q_{e}-q_{t}\right)=\ln q_{e}-k_{1} t
$$

" $k_{1}$ " can be calculated from the slope of the linear plot between $\ln \left(q_{e}-q_{t}\right)$ vs. " $t$ " for different adsorption parameters such as $\mathrm{pH}$, temperature, adsorbate concentration, adsorbent dose, particle size and agitation speed. Figure 9 shows a plot of $\log \left(q_{e}-q_{t}\right)$ vs. $t$ for biosorption of chromium using pseudo-first order kinetic model. The values of pseudo-first-order rate constants $(K)$ and equilibrium biosorption capacities $\left(q_{e}\right)$ were calculated from slopes and intercepts of straight lines. The values of pseudo-first-order equation parameters together with correlation coefficient are given in Table 7. The correlation coefficient obtained was 0.98 , which is indicative of a good correlation and calculated $q_{e}(1.305 \mathrm{mg} / \mathrm{g})$ determined from the model is not in a good agreement with the experimental $q_{e}(3.54 \mathrm{mg} / \mathrm{g})$.

Therefore, the pseudo-first-order model is not suitable for modeling the biosorption of chromium on to Gracilaria corticata powder.

Table 6. Optimum values of experimental and predicted \% biosorption.

\begin{tabular}{ccc}
\hline Parameters & Experimental & CCD \\
\hline $\mathrm{pH}\left(X_{1}\right)$ & 4 & 3.827 \\
Initial concentration $\left(X_{2}\right), \mathrm{mg} / \mathrm{L}$ & 20 & 19.35 \\
Biosorption dosage $\left(X_{3}\right), \mathrm{w}, \mathrm{g} / \mathrm{L}$ & 20 & 20.22 \\
Temperature $\left(X_{4}\right), \mathrm{K}$ & 303 & 306.02 \\
\% biosorption of chromium & 85.49 & 85.39 \\
\hline
\end{tabular}




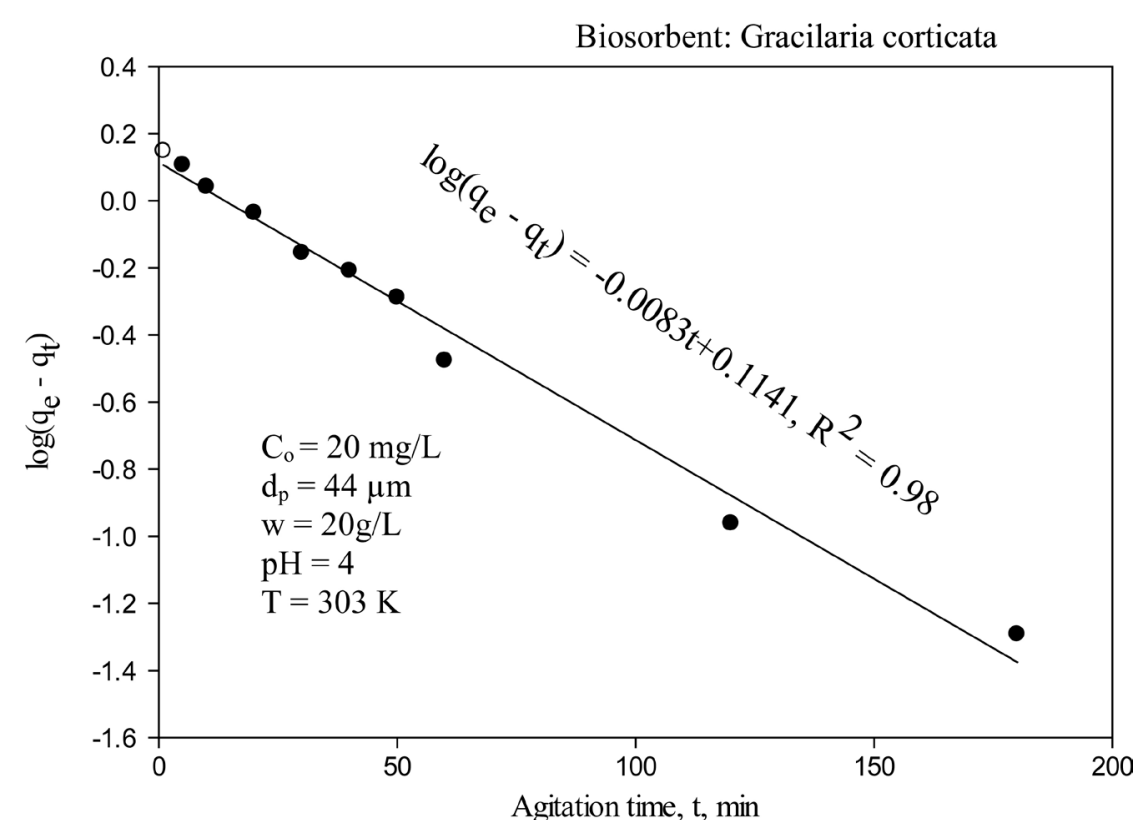

Figure 9. Pseudo first order kinetics for chromium biosorption.

Table 7. Pseudo first order constants.

\begin{tabular}{cccc}
\hline$K$ & $\boldsymbol{q}_{e}$ calculated $(\mathrm{mg} / \mathrm{g})$ & $\boldsymbol{q}_{e}$ experimental $(\mathrm{mg} / \mathrm{g})$ & $\boldsymbol{R}^{2}$ \\
\hline 0.019 & 1.305 & 3.54 & 0.98 \\
\hline
\end{tabular}

\subsubsection{Pseudo-Second-Order Kinetic Model}

The pseudo second order equation can be shown as:

$$
\frac{\mathrm{d} q}{\mathrm{~d} t}=k_{2}\left(q_{e}-q_{t}\right)^{2}
$$

On integration for boundary conditions when $t=0$ to $t>0$ and $q_{\mathrm{t}}=0$ to $q_{t}>0$ and further simplifications, Equation (6) becomes,

$$
\frac{t}{q_{t}}=\frac{1}{k_{2} q_{e}^{2}}+\frac{1}{q_{e}} t=\frac{1}{h}+\frac{1}{q_{e}} t
$$

where $h=k_{2} q_{e}^{2}$ is known as initial adsorption rate and " $k_{2}$ " is rate constant.

Figure 10 shows typical plot of pseudo-second-order equation for chromium biosorption on to Gracilaria corticata powder. A plot is drawn between $t / q_{t}$ vs. $t$. The straight lines in plot show good agreement with the pseudo-second-order kinetic model. The values of pseudo-second-order equation parameters together with correlation coefficient are listed in Table 8.

The correlation coefficient $\left(R^{2}\right)$ for the pseudo-second-order equation was found to be 0.99 . The calculated $q_{e}$ value also agrees with the experimental data. This strongly suggests that the biosorption of chromium on to Gracilaria corticata powder was most appropriately represented by a pseudo-second-order rate process [19].

\subsubsection{Intra-Particle Diffusion Kinetic Model}

The equation for intra-particle diffusion kinetic model is given as follows 


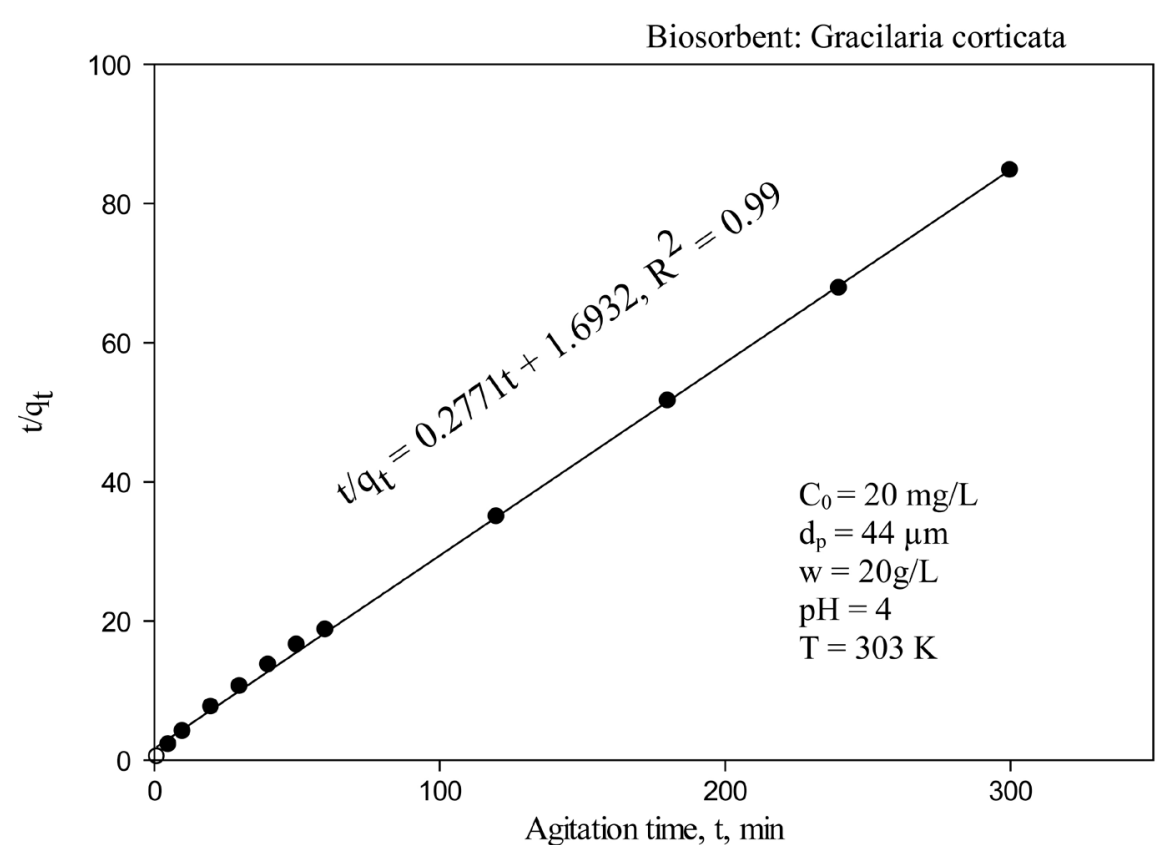

Figure 10. Pseudo second order kinetics for chromium biosorption.

Table 8. Pseudo second order constants.

\begin{tabular}{cccc}
\hline$K$ & $\boldsymbol{q}_{e}(\mathrm{mg} / \mathrm{g})$ calculated & $\boldsymbol{q}_{e}(\mathrm{mg} / \mathrm{g})$ experimental & $R^{2}$ \\
\hline 0.276 & 3.6 & 3.54 & 0.99 \\
\hline
\end{tabular}

$$
q_{t}=k_{i d} t^{1 / 2}
$$

On integrating the Equation (8), the equation becomes

$$
q_{t}=k_{i d} t^{1 / 2}+I
$$

$k_{d}=$ intra-particle diffusion rate constant, $\mathrm{mg} \cdot \mathrm{g}^{-1} \mathrm{~min}^{-1 / 2}$

$I=$ constant that gives idea about the boundary layer thickness, $\mathrm{mg} \cdot \mathrm{g}^{-1}$

The plot between $q_{t}$ and $t^{1 / 2}$ gives the values of coefficient of intra-particle diffusion $\left(k_{i d}\right)$ for different adsorption parameters (Table 9). The relationship between $q_{t}$ and $t^{0.5}$ was not linear over whole time range, indicating that there are several processes affecting the adsorption. The initial curved portion of the plot is attributed to boundary layer diffusion effects. The curved portion represents intra-particle diffusion controlled by the rate constant $k_{d}$ (Figure 11 ).

\subsection{Isotherm Models}

The mechanism for the interaction of chromium on the biosorbent site is based on the biosorption isotherms [20]. The biosorption isotherms are characterized by definite parameters, whose values express the surface properties and affinity of biosorbent for heavy metal ions adsorption [21]. Out of several isotherm equations, three have been applied for this study, Freundlich, Langmuir and Redlich-Peterson. In the present study, these models were tested and the various isotherms are presented in Figures 12-14. 
Table 9. Intra-particle diffusion constants.

\begin{tabular}{ccc}
\hline$X_{i}(\mathrm{mg} / \mathrm{g})$ & $K_{d}\left(\mathrm{mg} / \mathrm{g} \cdot \mathrm{min}^{0.5}\right)$ & $R^{2}$ \\
\hline 2.236 & 0.091 & 0.88 \\
\hline
\end{tabular}

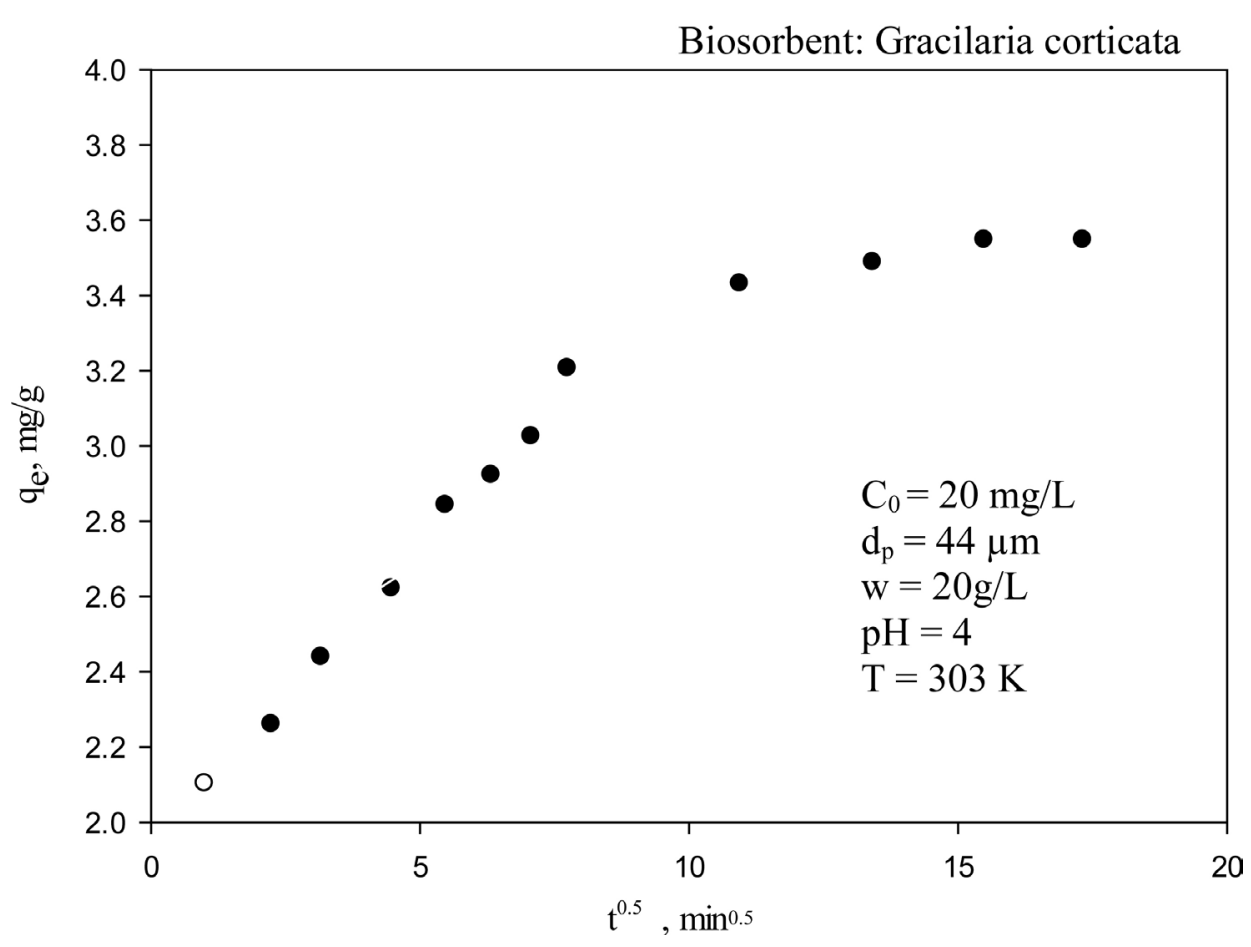

Figure 11. Intra-particle diffusion model for chromium biosorption.

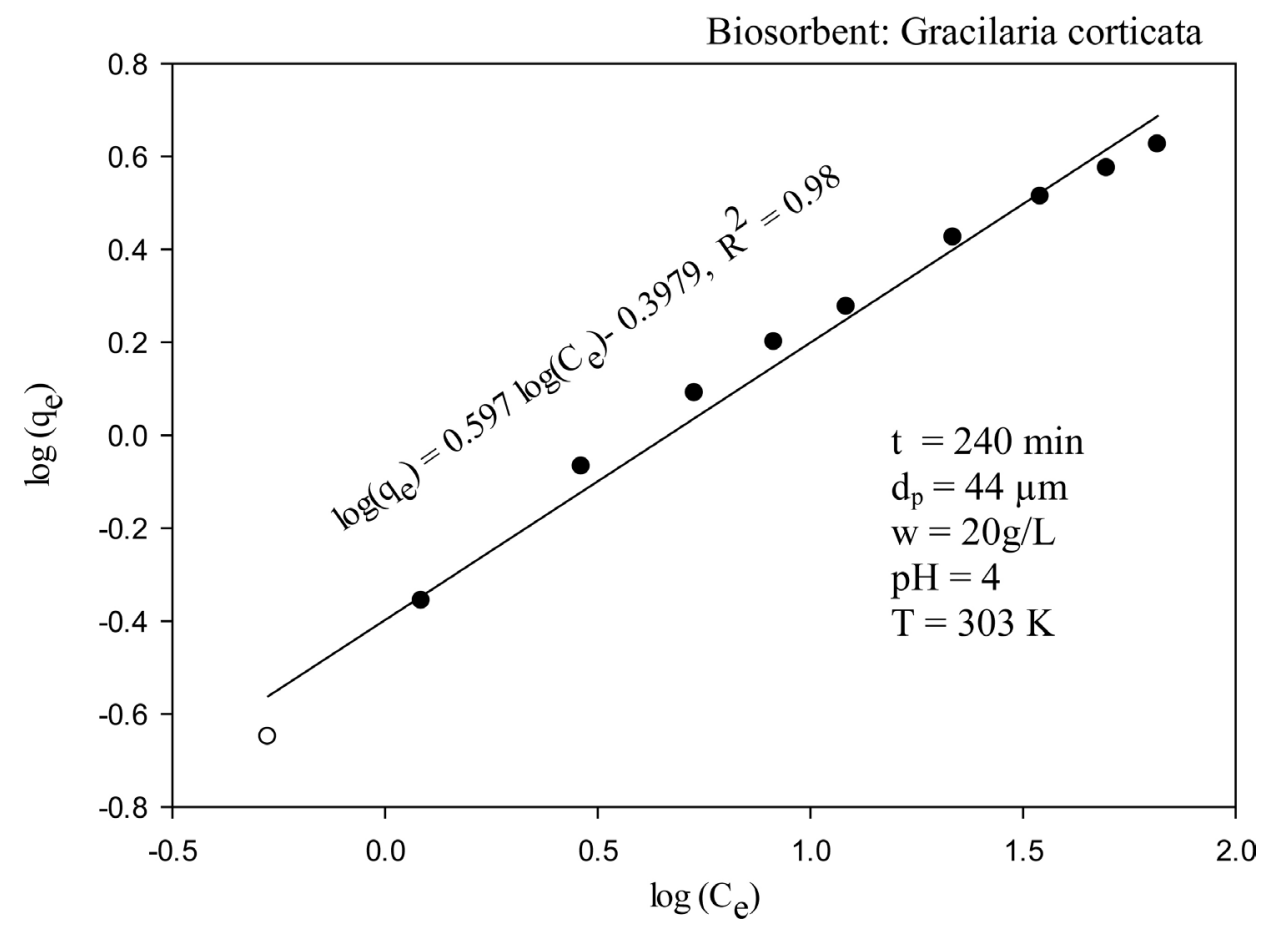

Figure 12. Freundlich isotherm for biosorption of chromium. 


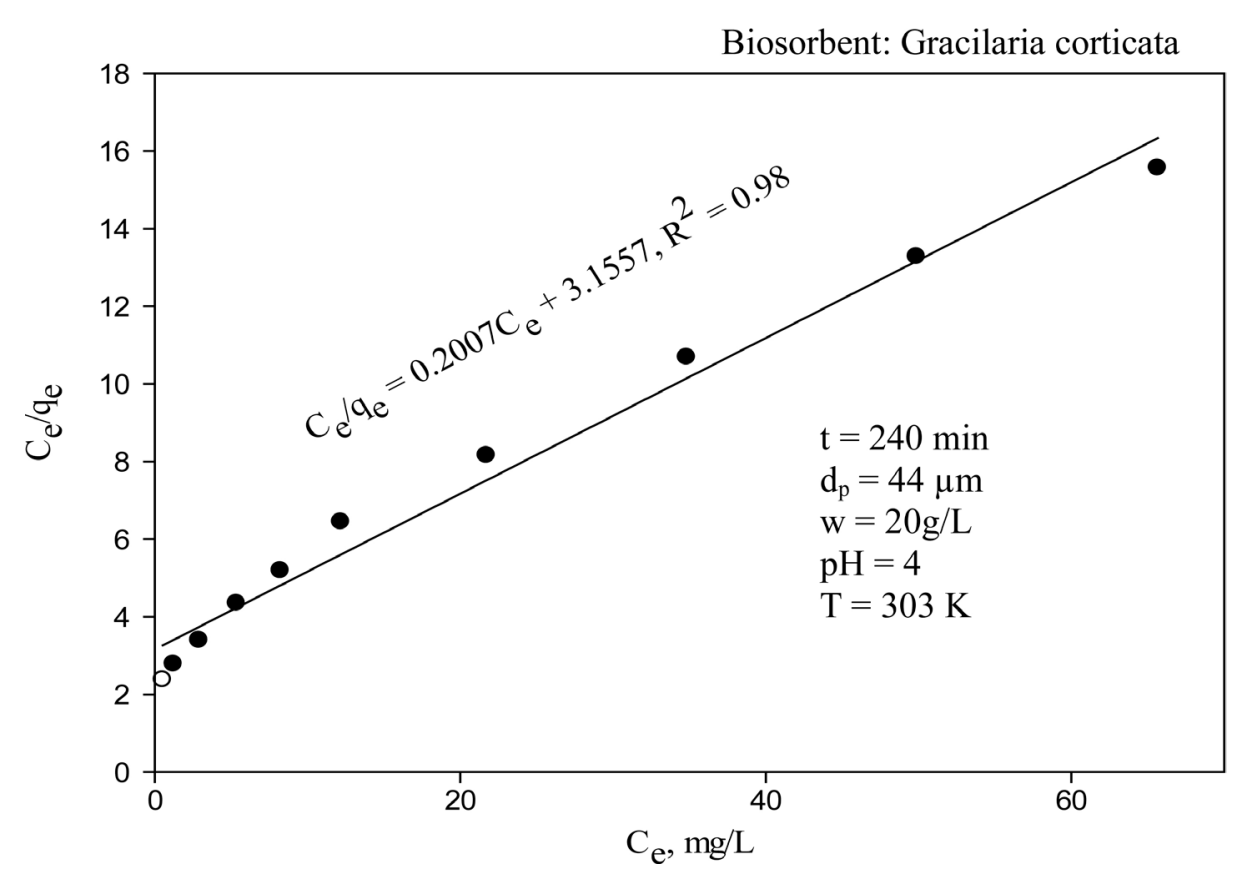

Figure 13. Langmuir isotherm for biosorption of chromium.

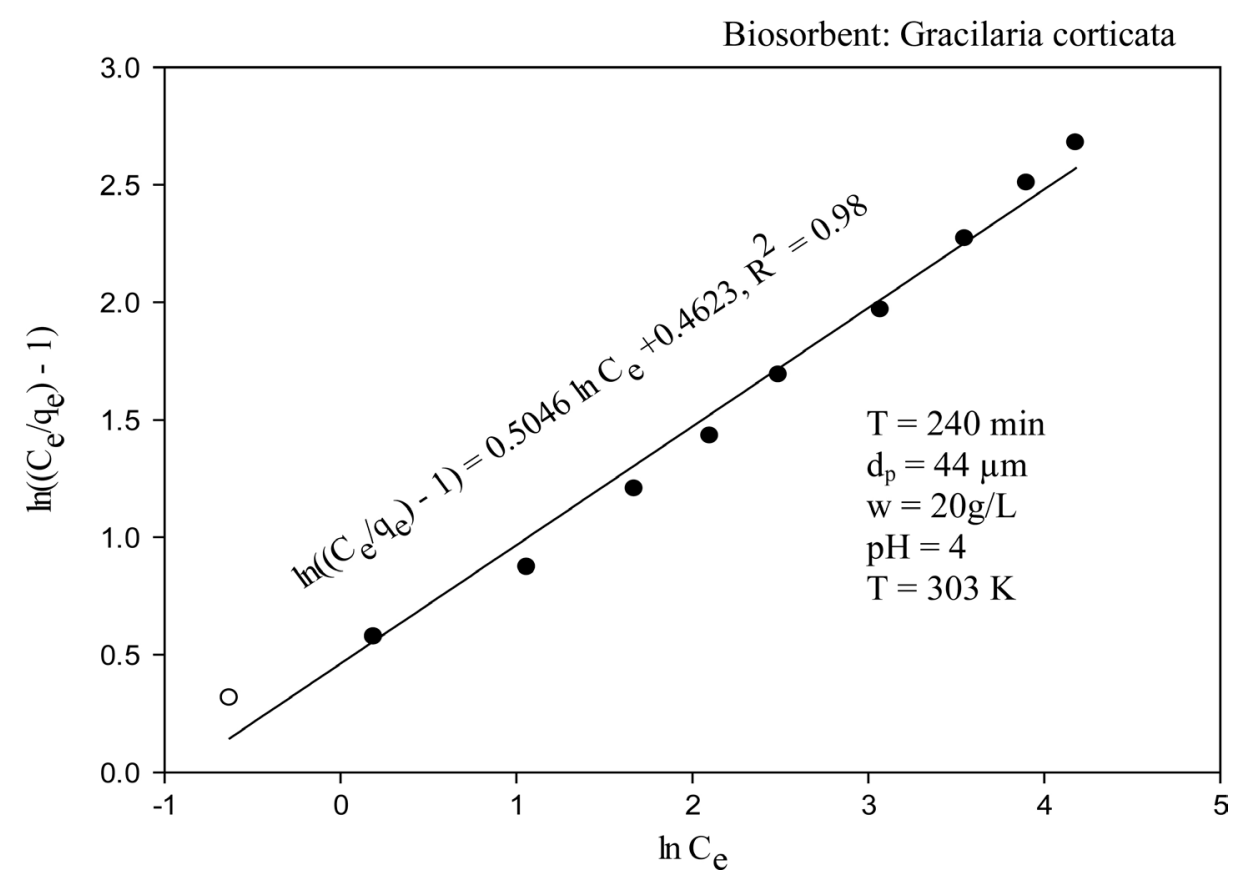

Figure 14. Redlich-Peterson isotherm for biosorption of chromium.

The parameters of Freundlich, Langmuir and Redlich-Peterson isotherms are given in Table 10. The Langmuir monolayer capacity was estimated to be $4.98 \mathrm{mg} / \mathrm{g}$. The results indicated that all models fit the data well.

\subsection{Thermodynamic Parameters}

A plot of $\log \left(q_{e} / C_{e}\right)$ versus $(1 / T)$ was found to be linear (Figure 15) and the thermo- 
Table 10. Isotherm model constants for chromium biosorption.

\begin{tabular}{cc}
\hline Freundlich & \\
\hline$K_{f}$ & 0.4 \\
$n$ & 0.597 \\
$R^{2}$ & 0.98 \\
\hline Langmuir & \\
\hline$q_{m}(\mathrm{mg} / \mathrm{g})$ & 4.982 \\
$b(\mathrm{~L} / \mathrm{mg})$ & 0.064 \\
$R^{2}$ & 0.98 \\
$R_{L}$ & 0.563 \\
\hline Redlich-Peterson & 1.5877 \\
$B(\mathrm{~L} / \mathrm{mg})$ & 0.5046 \\
$G$ & 0.98 \\
\hline$R^{2}$ & \\
\hline
\end{tabular}

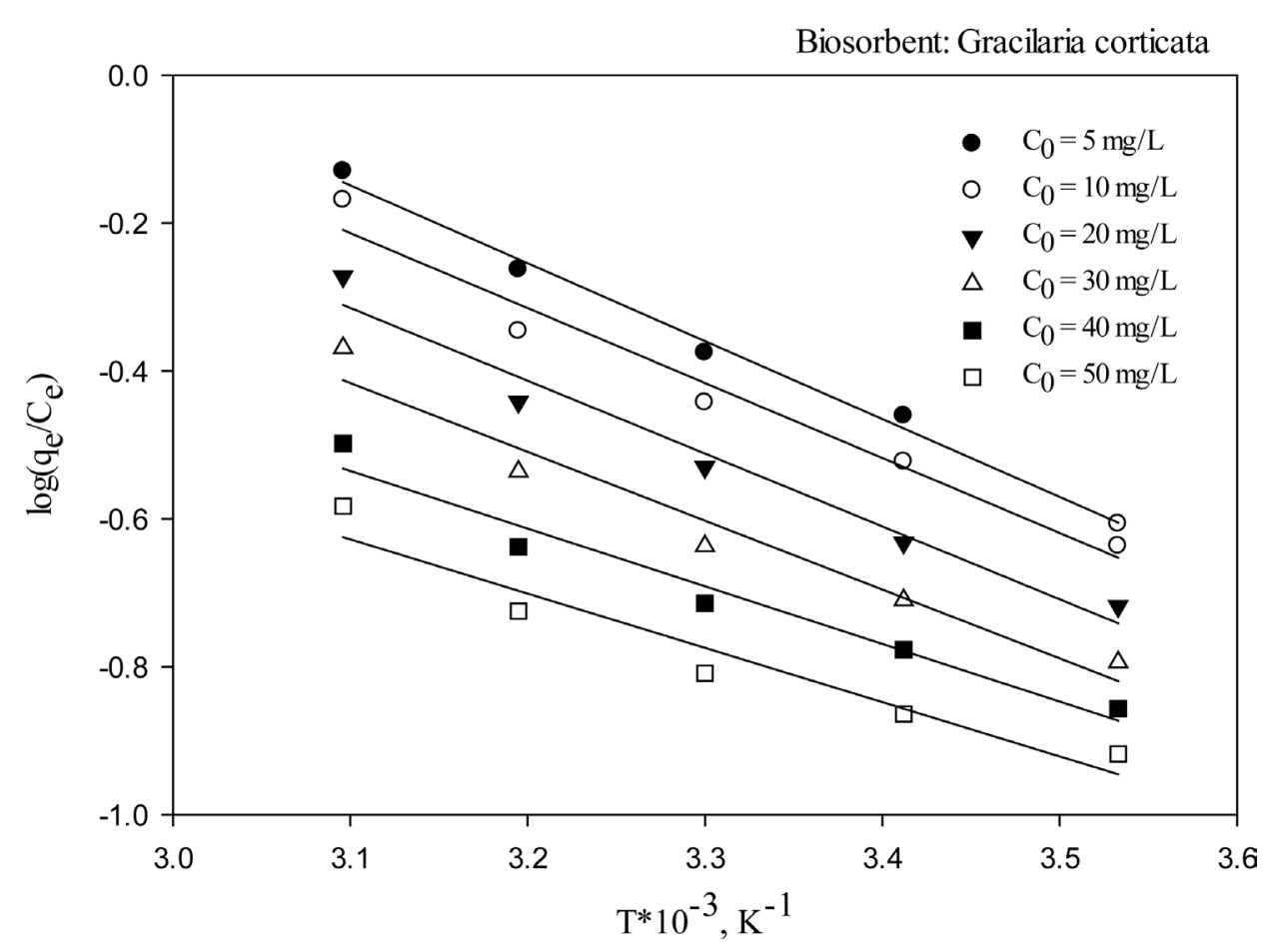

Figure 15. Van't Hoff's plot for biosorption of chromium.

dynamic parameters were calculated and tabulated in Table 11. One can see that the $\Delta H$ values are positive, indicating the endothermic nature of the adsorption process. Positive values of $\Delta S$ suggest the increased randomness at the solid-solution interface. Negative values of $\Delta G$ confirm the biosorption process is spontaneous, which becomes more negative with an increase in temperature. This indicates that a higher adsorption is actually occurred at higher temperatures [22] and at higher temperature, ions are 
readily desolvated and thereby their adsorption becomes more favorable [23].

\subsection{Characterization of Gracilaria corticata Powder}

\subsubsection{FTIR Spectrum of Gracilaria corticata Powder}

FTIR spectrum for untreated and treated powder is shown in Figure 16(a) and Figure 16(b). The broad band at $3421.83 \mathrm{~cm}^{-1}$ suggests stretching biosorption of $-\mathrm{OH}$. The band at $2922.25 \mathrm{~cm}^{-1}$ due to the presence of stretching $\mathrm{C}-\mathrm{H}$ vibrations in $\mathrm{CH}_{2}$ or $\mathrm{C}=\mathrm{C}$ $\mathrm{H}$ group. The band at $1735.99 \mathrm{~cm}^{-1}$ indicates the presence of stretching $\mathrm{C}=\mathrm{O}$ vibrations

Table 11. Thermodynamic parameters.

\begin{tabular}{cccccccc}
\hline \multirow{2}{*}{$\mathrm{C}_{0} \mathrm{mg} / \mathrm{L}$} & $\Delta \mathrm{S} \mathrm{J} /(\mathrm{mol}-\mathrm{K})$ & $\Delta H \mathrm{~J} / \mathrm{mol}$ & \multicolumn{5}{c}{$-(\Delta G), \mathrm{kJ} / \mathrm{mol}$} \\
\cline { 5 - 8 } & & & $283 \mathrm{~K}$ & $293 \mathrm{~K}$ & $303 \mathrm{~K}$ & $313 \mathrm{~K}$ & $323 \mathrm{~K}$ \\
\hline 5 & 59.69 & 20.175 & 16.87 & 17.468 & 18.06 & 18.66 & 19.25 \\
10 & 56.10 & 19.415 & 15.85 & 16.417 & 16.978 & 17.53 & 18.10 \\
20 & 54.45 & 18.86 & 15.39 & 15.93 & 16.47 & 17.02 & 17.56 \\
30 & 47.27 & 17.82 & 13.35 & 13.83 & 14.30 & 14.77 & 15.25 \\
40 & 36.05 & 14.93 & 10.18 & 10.54 & 10.91 & 11.26 & 11.62 \\
50 & 31.53 & 14.05 & 8.910 & 9.225 & 9.541 & 9.856 & 10.17 \\
\hline
\end{tabular}

Ф SHIMADZU

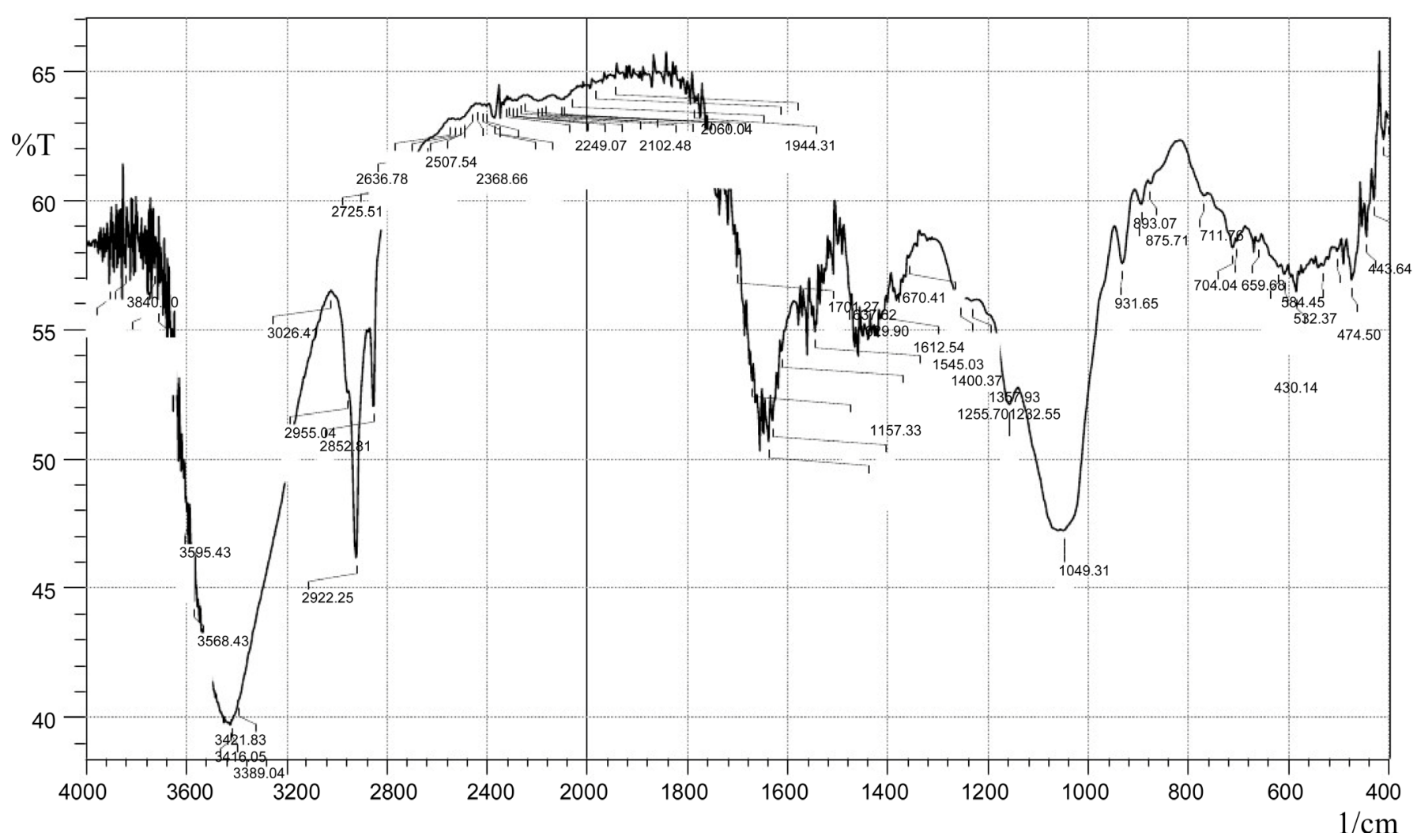

(a) 


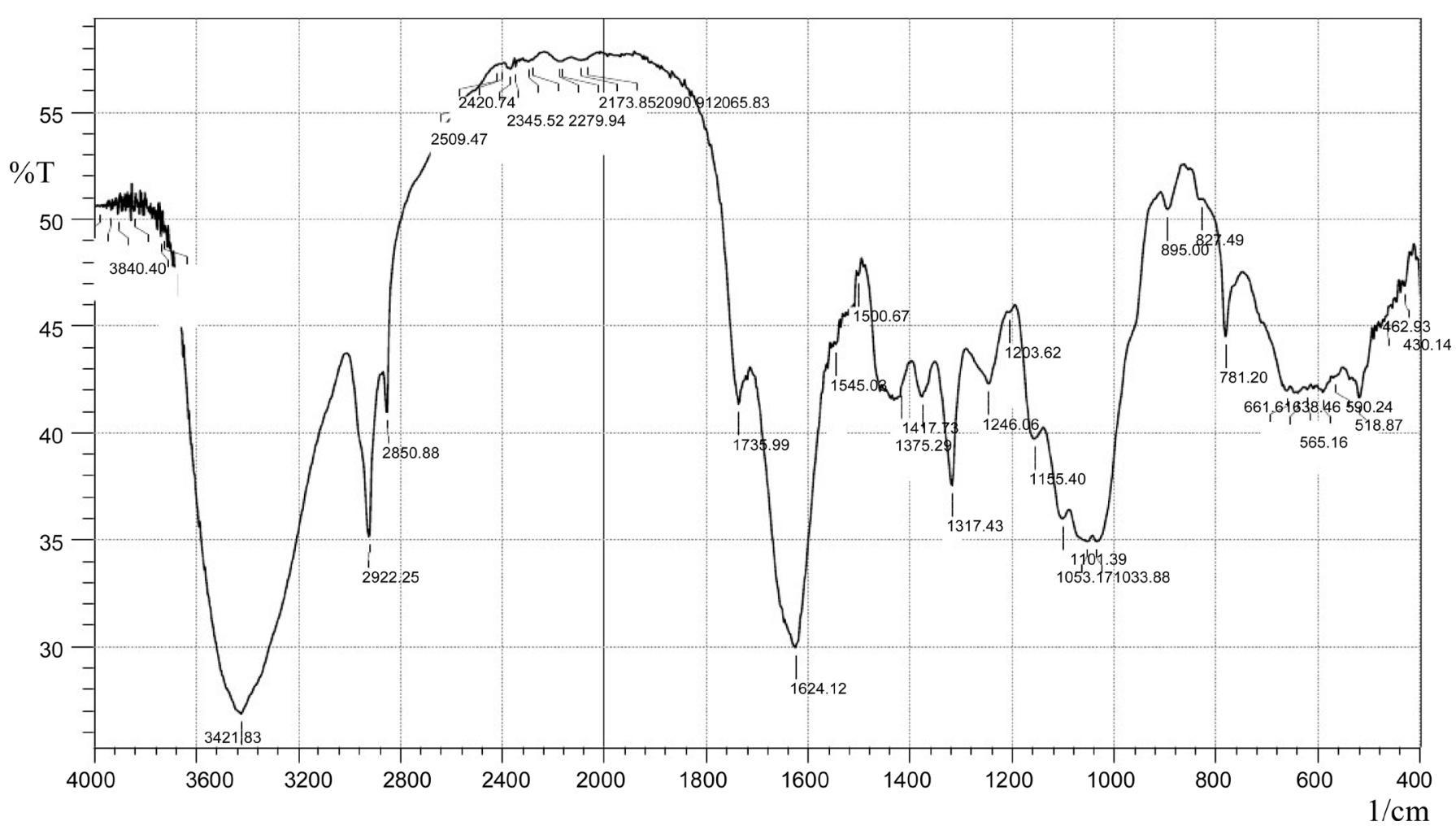

(b)

Figure 16. (a) FTIR spectrum of treated Gracilaria corticata powder; (b) FTIR spectrum of treated Gracilaria corticata powder.

arising from group such as lactone, quinine and carboxylic acids.

The band at $1624.12 \mathrm{~cm}^{-1}$ denotes the asymmetric and symmetric stretching COOvibrations or the skeletal $\mathrm{C}=\mathrm{C}$ aromatic vibrations, some bands in the fingerprint region could be attributed to the phosphate groups. Asymmetric and symmetric stretching vibration of ionic carboxylic groups (-COO-), appear at $1417.73 \mathrm{~cm}^{-1}, 1375.29$ $\mathrm{cm}^{-1}$ and aliphatic acid group. The vibration at $1246.06 \mathrm{~cm}^{-1}$ be attributed to deformation of $\mathrm{C}=\mathrm{O}$ and stretching formation of $-\mathrm{OH}$ of carboxylic acids and phenols. 1155 $\mathrm{cm}^{-1}$ suggests presence of $\mathrm{C}=\mathrm{N}$ stretching functional groups. Comparing IR spectra of Gracilaria corticata powder before and after biosorption, it is seen from Table 12 that biosorption bands shifted to higher values. These shifts may be attributed to the changes in counter ions associated with carboxylate and hydroxylate anions. This indicates that the main contributors in metal uptake may be acidic groups, carboxyl and hydroxyl group. These changes in FTIR spectra of biosorbents have also been observed in other biosorption using marine algae as biosorbents [24]-[27].

\subsubsection{X-Ray Diffraction for Gracilaria corticata Powder}

The XRD pattern of untreated Gracilaria corticata powder is shown in Figure 17(a) and XRD patterns of chromium treated Gracilaria corticata algae powder is shown in Figure 17(b). This shows that they have unaltered structures due to biosorption of chromium. 
Table 12. Shift of FTIR peaks for untreated and treated Gracilaria corticata powder.

\begin{tabular}{|c|c|c|}
\hline \multicolumn{3}{|c|}{ Wave number $\left(\mathrm{cm}^{-1}\right)$} \\
\hline Untreated sorbent & Treated sorbent & Description \\
\hline 3427.62 & 3421.83 & Hydrogen bonded $\mathrm{O}-\mathrm{H}$ stretching \\
\hline 2852.81 & 2850.88 & $\mathrm{C}-\mathrm{H}$ stretching \\
\hline 2507.54 & 2509.47 & ------- \\
\hline 2293.44 & 2297.30 & -------- \\
\hline 2058.11 & 2065.83 & -------- \\
\hline 1730.21 & 1735.99 & $\mathrm{C}=\mathrm{O}$ stretching in carboxyl \\
\hline 1627.97 & 1624.12 & $\mathrm{C}=\mathrm{O}$ stretching \\
\hline 1570.11 & ----- & $\mathrm{C}-\mathrm{N}$ stretching in -CO-NH- \\
\hline 1419.66 & 1417.73 & $\mathrm{O}-\mathrm{H}$ in plane bending (carboxyl) \\
\hline 1049.31 & 1053.17 & $\mathrm{C}-\mathrm{OH}$ stretching \\
\hline 893.07 & 895.00 & $\mathrm{C}-\mathrm{H}$ stretching \\
\hline 779.27 & 781.20 & Characteristic of substituted benzene \\
\hline 586.38 & 590.24 & C-Br stretching \\
\hline 468.72 & 462.93 & C-I stretching \\
\hline
\end{tabular}

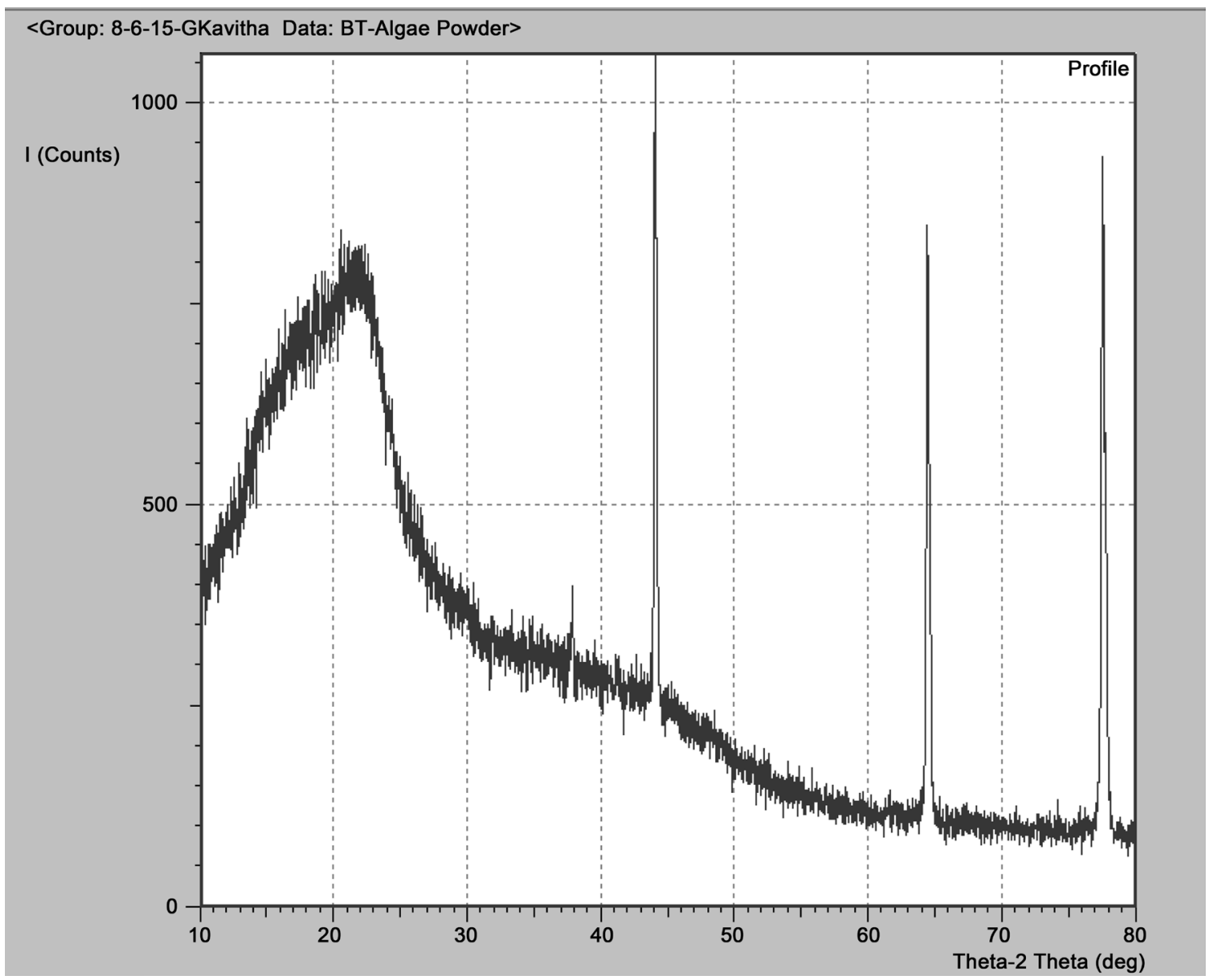

(a) 


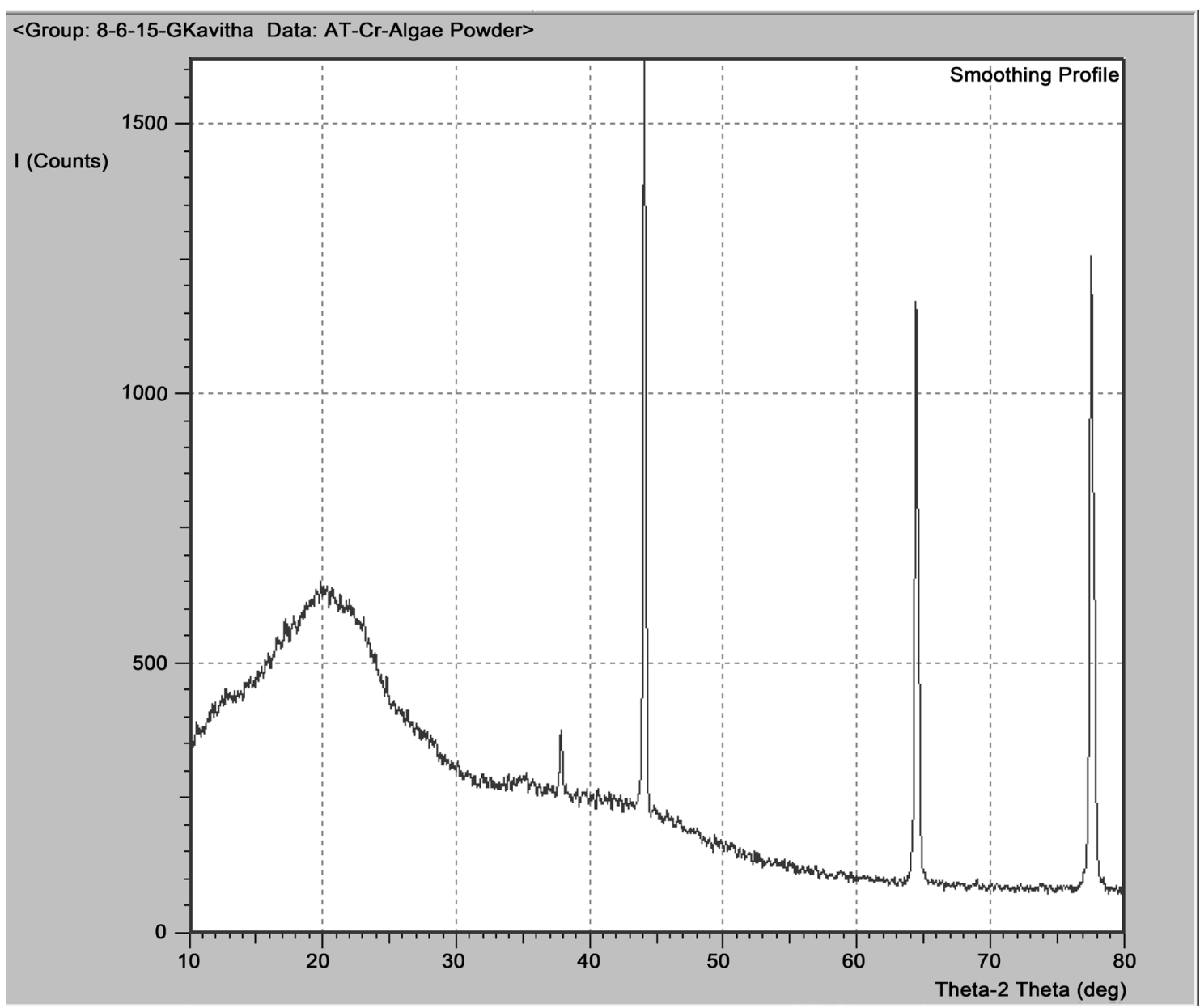

(b)

Figure 17. (a) XRD pattern of untreated Gracilaria corticata powder; (b) XRD pattern of treated Gracilaria corticata powder.

\subsubsection{SEM Analysis for Untreated and Treated Gracilaria corticata Powder}

The surface morphology of Gracilaria corticata powder was explained by scanning electron microscopy (SEM) the corresponding SEM micrographs being obtained using at an accelerating voltage of $12 \mathrm{kV}$ (Hitachi SE 900) at 5000× magnification. At such magnification, the Gracilaria corticata powder showed rough areas of surface on which micro pores were clearly identifiable in Figure 18(a). This structural feature may be important since it increases the total surface area [28]. The structure of treated Gracilaria corticata powder is shown in Figure 18(b) and indicates a change of structure and had a tendency to form agglomerates [29]. The differences in the fracture surface clearly confirm the presence of the molecules on the waste biomass (Table 13).

\section{Conclusions}

Both experimental and theoretical studies are carried out for equilibrium, kinetics and thermodynamic parameters of chromium biosorption from aqueous solutions by Gracilaria corticata powder. The analysis of the experimental and theoretical data, results in 


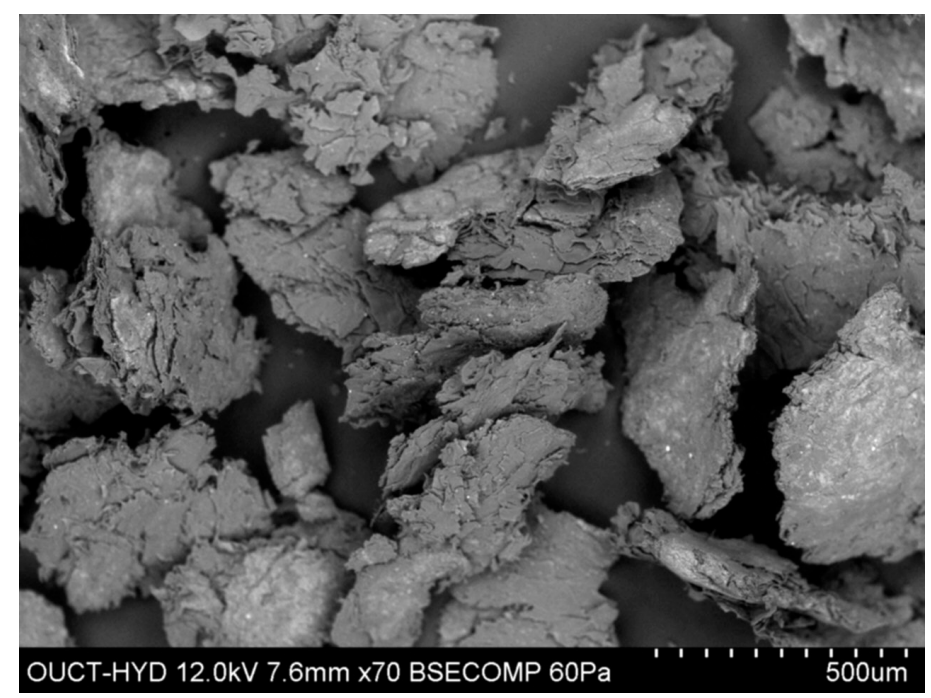

(a)

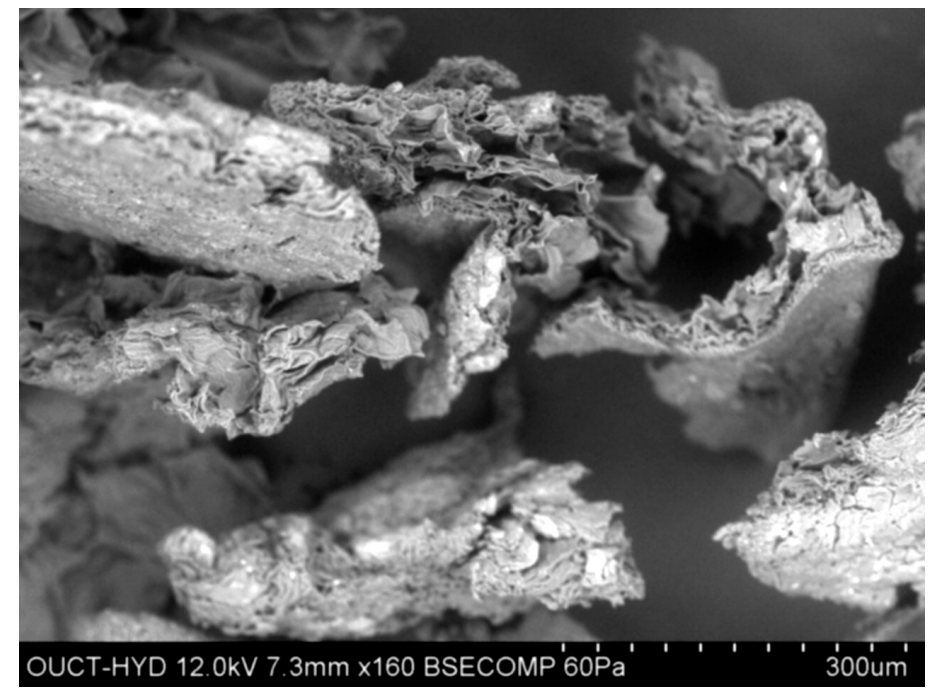

(b)

Figure 18. (a) Electron micrograph of untreated Gracilaria corticata powder; (b) Electron micrograph of treated Gracilaria corticata powder.

Table 13. Comparison of chromium uptake capacities of various biosorbents with those of biosorbent used in the present investigation.

\begin{tabular}{cc}
\hline Biosorbent & Metal Uptake, mg/g \\
\hline Aspergillus flavus [30] & 0.335 \\
Clodophara crispate (green algae) [31] & 6.2 \\
Rhizopus arrhizus [32] & 5.1 \\
Spirogyra sp. (green algae) [33] & 14.7 \\
Pilayella littoralis (brown algae) [34] & 4.68 \\
Cystoseira indica (brown algae) [35] & 17.8 \\
Gracilaria corticata (red algae) & 4.982 \\
\hline
\end{tabular}


the following conclusions:

1) The biosorption of chromium onto Gracilaria cortiata is spontaneous.

2) Percentage removal of chromium from the aqueous solution increases significantly from $69.12 \%$ to $76.14 \%$ with an increase in $\mathrm{pH}$ from 1 to 4 . Thereafter percentage removal decreases for further increase in $\mathrm{pH}$.

3) The percentage removal is increased from $56.23 \%$ to $89.37 \%$ as chromium initial concentration is decreased from 150 to $5 \mathrm{mg} / \mathrm{L}$.

4) The use of statistical experimental design to optimize process conditions for maximal biosorption of chromium from aqueous solution using CCD involving RSM at the end of $240 \mathrm{~min}$ biosorption was involved in the present study. When the processing parameters are set as: $\mathrm{pH}=3.827, \mathrm{C}_{0}=19.35 \mathrm{mg} / \mathrm{L}, \mathrm{w}=20.22 \mathrm{~g} / \mathrm{L}$, and $\mathrm{T}=306.02 \mathrm{~K}$, the maximum biosorption of chromium (85.39\%) onto Gracilaria corticata powder was observed.

5) The Freundlich and Langmuir adsorption models were used for the mathematical description of the biosorption of chromium and the isotherms constants were evaluated to compare the biosorptive capacity of Gracilaria corticata powder. The maximum monolayer coverage capacity of Gracilaria corticata powder for chromium ions is 4.982 $\mathrm{mg} / \mathrm{g}$.

6) The kinetic studies show that the biosorption of chromium is better described by pseudo second order kinetics.

7) The adsorption mechanism explained by Weber and Morris equation concludes that intra-particle diffusion model is not the rate limiting step.

8) The positive values of enthalpy change $(\Delta H)$ indicated an endothermic and irreversible process.

\section{References}

[1] Kowalski, Z. (1994) Treatment of Chromic Tannery Wastes. Journal of Hazardous Materials, 37, 137-144. http://dx.doi.org/10.1016/0304-3894(94)85042-9

[2] Demirbas, E., Kobya, M., Senturk, E. and Ozkan, T. (2004) Adsorption Kinetics for the Removal of Chromium (VI) from Aqueous Solutions on the Activated Carbons Prepared from Agricultural Wastes. Water $S A, 30,533-539$. http://dx.doi.org/10.4314/wsa.v30i4.5106

[3] Doke, K., Khan, E. and Gaikwad, V. (2013) Diffusion Mechanisms of Biosorption of Cr(VI) onto Powdered Cotton Stalk. Journal of Dispersion Science and Technology, 34, 1347-1355. http://dx.doi.org/10.1080/01932691.2012.745376

[4] Cazon, J.P.H., Benitez, L., Donati, E. and Viera, M. (2012), Biosorption of Chromium (III) by Two Brown Algae Macrocysis pyrifera and Undaria pinnatifida: Equilibrium and Kinetic Study. Engineering in Life Sciences, 12, 95-103. http://dx.doi.org/10.1002/elsc.201100098

[5] Jia, C.-G., Zhang, Y.-P., Wang, H., Ou, G.-N., Liu, Q.-M. and Lin, J.-M. (2014) Rapid Biosorption and Reduction Removal of $\mathrm{Cr}(\mathrm{VI})$ from Aqueous Solution by Dried Seaweeds. Journal of Central South University, 21, 2801-2809. http://dx.doi.org/10.1007/s11771-014-2243-6

[6] Siva Prakash, A., Aravindhan, R., Raghava Rao, J. and Unni Nair, B. (2009) Kinetics and Equilibrium Studies on the Biosorption of Hexavalent Chromium from Aqueous Solutions Using Bacillus Subtilis Biomass. Applied Ecology and Environmental Research, 7, 45-57. 
http://dx.doi.org/10.15666/aeer/0701 045057

[7] Puentes-Cardenas, I.J., Pedroza-Rodriguez, A.M., Suazo-Madrid, E.A., Navarrete-Lopez, M., Villegas-Garrido, T.L. and Cristiani-Urbina, E. (2012) Biosorption of Trivalent Chromium from Aqueous Solutions by Pleurotus ostreatus Biomass. Environmental Engineering and Management Journal, 11, 1741-1752.

[8] Saurav, K. and Kannabiran, K. (2011) Biosorption of Cr(III) and Cr(VI) by Strptomyces VITSVK9 spp. Annals of Microbiology, 61, 833-841.

http://dx.doi.org/10.1007/s13213-011-0204-y

[9] Gopalakrishnan, S., Kannadasan, T., Velmurugan, S., Muthu, S. and Vinoth Kumar, P. (2013) Biosorption of Chromium(VI) from Industrial Effluent Using Neem Leaf Adsorbent. Research Journal of Chemical Sciences, 3, 48-53.

[10] Cossich, E.S., Tavares, C.R.G. and Ravagnani, T.M.K. (2002) Biosorption of Chromium(III) by Sargassum sp. Biomass. Electronic Journal of Biotechnology, 5, 1-7.

[11] Kumar, R., Bishnoi, N.R., Garima and Bishnoi, (2008) Biosorption of Chromium (VI) from Aqueous Solution and Electroplating Wastewater Using Fungal Biomas. Chemical Engineering Journal, 135, 202-208. http://dx.doi.org/10.1016/j.cej.2007.03.004

[12] Gupta, V.K. and Ali, I. (2004) Removal of Lead and Chromium from Wastewater Using Bagasse Fly Ash-A Sugar Industry Waste. Journal of Colloid and Interface Science, 271, 321-328. http://dx.doi.org/10.1016/j.jcis.2003.11.007

[13] Rao, M., Parvate, A.V. and Bhole, A.G. (2002) Process Development for Removal of Copper and Lead from Aqueous Solution by Low Cost Material. J Envir Poll, 22, 17-25.

[14] Bishnoi, N.R. (2004) Biosorption of Cu (II) from Aqueous Solution Using Algal Biomass. Journal of Scientific \& Industrial Research, 63, 813-816.

[15] Ucun, H.Y., Bayhan, Y.K., Kaya, Y., Cakici, A. and Algur, O.F. (2002) Biosorption of Chromium (VI) from Aqueous Solution by Cone Biomass of Pinus sylvestris. Bioresource Technology, 85, 155-158. http://dx.doi.org/10.1016/S0960-8524(02)00086-X

[16] Baral, S.S., Das, N., Chaudhury, G.R. and Das, S.N. (2009) A Preliminary Study on the Adsorptive Removal of Cr (VI) Using Seaweed, Hydrilla verticillata. Journal of Hazardous Materials, 171, 358-369. http://dx.doi.org/10.1016/j.jhazmat.2009.06.011

[17] Hanif, M.A., Nadeema, R., Zafara, M.N., Akhtar, K. and Bhatti, H.N. (2007) Kinetic Studies for Ni (II) Biosorption from Industrial Wastewater by Cassia fistula (Golden Shower) Biomass. Journal of Hazardous Materials, 145, 501-505. http://dx.doi.org/10.1016/j.jhazmat.2007.01.022

[18] Anand Kumar, J. and Mandal, B. (2011) Adsorption of Chromium (VI) and Rhodamine B by Surface Modified Tannery Waste: Kinetic, Mechanistic and Thermodynamic Studies. Journal of Hazardous Materials, 186, 1088-1096. http://dx.doi.org/10.1016/j.jhazmat.2010.11.104

[19] Sari, A. and Tuzen, M. (2008) Biosorption of Total Chromium from Aqueous Solution by Red Algae (Ceramium virgatum): Equilibrium, Kinetic and Thermodynamic Studies. Journal of Hazardous Materials, 160, 349-355. http://dx.doi.org/10.1016/j.jhazmat.2008.03.005

[20] Pillai, S.S., Mullassery, M.D., Fernandez, N.B., Girija, N., Geetha, P. and Koshy, M. (2013) Biosorption of $\mathrm{Cr}(\mathrm{VI})$ from Aqueous Solution by Chemically Modified Potato Starch: Equilibrium and Kinetic Studies. Ecotoxicology and Environmental Safety, 92, 199-205. http://dx.doi.org/10.1016/j.ecoenv.2013.01.020

[21] Manzoor, Q., Nadeem, R., Iqbal, M., Saeed, R. and Ansari, T.M. (2013) Organic Acids Pretreatment Effect on Rosa bourbonia Phyto-Biomass for Removal of $\mathrm{Pb}$ (II) and $\mathrm{Cu}$ (II) from Aqueous Media. Bioresource Technology, 132, 446-452. http://dx.doi.org/10.1016/j.biortech.2013.01.156 
[22] Yavuz, O., Altunkaynak, Y. and Guzel, F. (2003) Removal of Copper, Nickel, Cobalt and Manganese from Aqueous Solution by Kaolinite. Water Research, 37, 948-952.

http://dx.doi.org/10.1016/S0043-1354(02)00409-8

[23] Chen, C.L. and Wang, X.K. (2006) Adsorption of Ni (II) from Aqueous Solution Using Oxidized Multiwall Carbon Nanotubes. Indian Engineering Chemistry Research, 45, 91449149. http://dx.doi.org/10.1021/ie060791z

[24] Cazon, J.P.H., Benitez, L., Donati, E. and Viera, M. (2012).Biosorption of Chromium (III) by Two Brown Algae Macrocystis pyrifera and Undaria pinnatifida: Equilibrium and Kinetic Study. Engineering in Life Sciences, 12, 95-103. http://dx.doi.org/10.1002/elsc.201100098

[25] Cazon, J.P.H., Donati, M.V.E. and Guibal, E. (2011) Biosorption of Mercury by Macrocystis pyrifera and Undaria pinnatifida. Influence of Zinc, Cadmium and Nickel. Journal of Environmental Sciences, China, 23, 1778-1786. http://dx.doi.org/10.1016/S1001-0742(10)60650-X

[26] Bueno, B.Y.M., Torem, M.L., Molina, F. and de Mesquita, L.M.S. (2008) Biosorption of Lead (II), Chromium (III) and Copper (II) by R. opacus. Equilibrium and Kinetic Studies. Minerals Engineering, 21, 65-75. http://dx.doi.org/10.1016/j.mineng.2007.08.013

[27] Jacques, R.A., lima, E.C., Dias, S.L.P. and Mazzacato, A.C. (2007) Yellow Passion Fruit Shell as Biosorbent to Remove $\mathrm{Cr}$ (III) and $\mathrm{Pb}$ (II) from Aqueous Solution. Separation and Purification Technology, 57, 193-198. http://dx.doi.org/10.1016/j.seppur.2007.01.018

[28] Bayramoglu, G., Celik, G. and Arica, M.Y. (2006) Biosorption of Reactive Blue 4 Dyes by Native and Treated Fungus Phanerocheate chrysosporium: Batch and Continuous Flow System Studies. Journal of Hazardous Materials, 137, 1689-1697.

http://dx.doi.org/10.1016/j.jhazmat.2006.05.005

[29] Tsai, W.T., Hsu, H.C., Su, T.Y., Lin, K.Y. and Lin, C.M. (2008) Removal of Basic Dye (Methylene Blue) from Wastewaters Utilizing Beer Brewery Waste. Journal of Hazardous Materials, 154, 73-78. http://dx.doi.org/10.1016/j.jhazmat.2007.09.107

[30] Deepa, K.K., Sathish Kumar, M., Binupriya, A.R., Murugesan, G.S., Swaminathan, K. and Yun, S.E. (2006) Sorption of Cr (VI) from Dilute Solutions and Wastewater by Live and Pretreated Biomass of Aspergillus flavus. Chemosphere, 62, 833-840. http://dx.doi.org/10.1016/j.chemosphere.2005.04.087

[31] Donmez, G., Aksu, Z., Ozturk, A. and Kutsal, T. (1999) A Comparative Study on Heavy Metal Biosorption Characteristics of Some Algae. Process Biochemistry, 34, 885-892. http://dx.doi.org/10.1016/S0032-9592(99)00005-9

[32] Sag, Y., Yalcuk, A. and Kutsal, T. (2001) Use of Mathematical Model for Prediction of the Performance of the Simultaneous Biosorption of $\mathrm{Cr}(\mathrm{VI})$ and $\mathrm{Fe}(\mathrm{II})$ on Rhizopus arrhizus in a Semi-Batch Reactor. Hydrometallurgy, 59, 77-87. http://dx.doi.org/10.1016/S0304-386X(00)00143-2

[33] Gupta, V.K., Shrivastava, A.K. and Jain, N. (2001) Biosorption of Chromium (VI) from Aqueous Solutions by Green Algae Spirogyra Species. Water Research, 35, 4079-4085. http://dx.doi.org/10.1016/S0043-1354(01)00138-5

[34] Carrilho, E.N. and Gilbert, T.R. (2000) Assessing Metal Sorption on the Marine Algae Pilayella littoralis. Journal of Environmental Monitoring, 2, 410-415. http://dx.doi.org/10.1039/b004128i

[35] Shaik, B., Murthy, Z.V.P. and Jha, B. (2008) Biosorption of Hexavalent Chromium by Chemically Modified Seaweed, Cystoseira indica. Chemical Engineering Journal, 137, 480488. http://dx.doi.org/10.1016/j.cej.2007.04.038 


\section{Nomenclature}

B Redlich-Peterson isotherm constant, L/mg

b Langmuir equilibrium constant, $\mathrm{L} / \mathrm{mg}$

$\mathrm{C}_{0}$ Initial concentration of chromium in aqueous solution, $\mathrm{mg} / \mathrm{L}$

$\mathrm{C}_{\mathrm{t}}$ Concentration of chromium in aqueous solution after " $\mathrm{t}$ " $\mathrm{min}, \mathrm{mg} / \mathrm{L}$

$\mathrm{C}_{\mathrm{e}}$ Equilibrium biosorption concentration of chromium, mg/L

$\mathrm{d}_{\mathrm{p}}$ Adsorbent size, $\mu \mathrm{m}$

g Redlich-Peterson isotherm exponent

$\Delta \mathrm{G}$ Change in Gibbs free energy, $\mathrm{kJ} / \mathrm{mol}$

$\Delta \mathrm{H}$ Heat of reaction, $\mathrm{J} / \mathrm{mol}$

$\mathrm{K}_{\mathrm{ad}}$ First order rate constant, $\mathrm{min}^{-1}$

$\mathrm{K}$ Second order rate constant, g/mg-min

$\mathrm{K}_{\mathrm{f}}$ Freundlich coefficient for chromium in aqueous solution, $\mathrm{L} / \mathrm{g}$

$\mathrm{Kd}$ Intra-particle diffusion constant, $\mathrm{mg} / \mathrm{g} \cdot \mathrm{min}^{0.5}$

$\mathrm{m}$ Amount of adsorbent consumed per $1 \mathrm{~L}$ aqueous solution, $\mathrm{mg} / \mathrm{L}$

$\mathrm{n}$ Freundlich constant for chromium in the aqueous solution

$\mathrm{q}_{\mathrm{e}}$ Mass of solute adsorbed per mass of adsorbent at equilibrium, $\left(\mathrm{C}_{\mathrm{o}}-\mathrm{C}_{\mathrm{e}}\right) / \mathrm{m}, \mathrm{mg} / \mathrm{g}$

$\mathrm{q}_{\mathrm{t}} \quad$ Mass of solute adsorbed per mass of adsorbent at " $\mathrm{t}$ " $\mathrm{min},\left(\mathrm{C}_{\mathrm{o}}-\mathrm{C}_{\mathrm{t}}\right) / \mathrm{m}, \mathrm{mg} / \mathrm{g}$

$\mathrm{q}_{\mathrm{m}}$ Langmuir monolayer adsorption capacity, $\mathrm{mg} / \mathrm{g}$

R Gas constant, $8.314 \mathrm{~J} / \mathrm{mole}-\mathrm{K}$

$\mathrm{R}^{2}$ Correlation coefficient

$\mathrm{R}_{\mathrm{L}}$ Separation factor, $1 /\left(1+\mathrm{bC}_{\mathrm{e}}\right)$

$\Delta \mathrm{S}$ Entropy change, $\mathrm{J} / \mathrm{mol}-\mathrm{K}$

$\mathrm{t}$ Agitation time, min

$\mathrm{T}$ Absolute temperature, $\mathrm{K}$

$\mathrm{V}$ Volume of aqueous solution, $\mathrm{mL}$

$\mathrm{w}$ Adsorbent dosage in $1 \mathrm{~L}$ of aqueous solution, $\mathrm{mg} / \mathrm{L}$ or $\mathrm{g}$

\section{Submit or recommend next manuscript to OALib Journal and we will provide best} service for you:

- Publication frequency: Monthly

- 9 subject areas of science, technology and medicine

- Fair and rigorous peer-review system

- Fast publication process

- Article promotion in various social networking sites (LinkedIn, Facebook, Twitter, etc.)

- Maximum dissemination of your research work

Submit Your Paper Online: Click Here to Submit

Contact Us: service@oalib.com 